\title{
Enrichment of Luminescence via Incorporation of Fluxes in La2Zr207:Tb3+ Nanophosphors: One Material, Many Possibilities-Latent Fingerprint Visualization, Anti- counterfeiting, Luminescent Flexible Films
}

\section{R. Lavanya} University College of Science, Tumkur University

G. P. Darshan ( $\nabla$ darshubavimane@gmail.com )

FMPS, M. S. Ramaiah University of Applied Sciences

\section{J. Malleshappa}

University College of Science, Tumkur University

H. B. Premkumar

FMPS, M. S. Ramaiah University of Applied Sciences

S. C. Sharma

Jain Deemed to be University

\section{S. A. Hariprasad}

Jain Deemed to be University

\section{H. Nagabhushana}

Tumkur University

\section{Research Article}

Keywords: Nanophosphors, Fluxes, Solution combustion synthesis, Latent fingerprints, Anti-counterfeiting, Luminescent films

Posted Date: December 20th, 2021

DOI: https://doi.org/10.21203/rs.3.rs-1158151/v1

License: (c) (i) This work is licensed under a Creative Commons Attribution 4.0 International License. Read Full License 


\section{Abstract}

Engineering of single material with multidirectional applications is of crucial for improving the productivity, low cost, flexibility and least power consumption, etc. To achieve these requirements, novel design structures and high performance materials are in urgent need. Lanthanide-doped nanophosphors have greatest strengths and ability in order to tuning its applications in various dimensions. However, nanophosphor applications in latent fingerprints visualization, anti-counterfeiting and luminescent gels/films are still in its infancy. This study demonstrated a simple strategy to enhance the luminescence of $\mathrm{Tb}^{3+}$ doped (1-11 mol \%) $\mathrm{La}_{2} \mathrm{Zr}_{2} \mathrm{O}_{7}$ nanophosphors by conjugating the fluxes via simple solution combustion route. The photoluminescence spectra reveal intense peaks at $\sim 491$, 546,587 and $622 \mathrm{~nm}$ arises from ${ }^{5} \mathrm{D}_{4} \diamond^{7} \mathrm{~F}_{\mathrm{J}}(\mathrm{J}=6,5,4,3)$ transitions of $\mathrm{Tb}^{3+}$ ions, respectively. The highest emission intensity was achieved in the $\mathrm{NH}_{4} \mathrm{Cl}$ flux assisted nanophosphor as compared to $\mathrm{NaBr}$ and $\mathrm{NH}_{4} \mathrm{~F}$. $\mathrm{The}$ colorimetric images of fingerprints visualized using optimized nanophosphor on forensic related surfaces exhibit level -III ridge details, including sweat pores, width of the ridges, bifurcation angle, successive distance between sweat pores, etc. These results are decisive parameters which clearly supports the statement "no two persons have ever been found to have the same fingerprints". The anti-counterfeiting security ink was formulated using nanophosphor and designed various patterns by simple screen printing and dip pen technology. The encoded information was decrypted only under ultraviolet $254 \mathrm{~nm}$ light. All the designed patterns are not just what it looks/feels like and how it works. As a synergetic contribution of enhanced luminescence of the prepared nanophosphor, the fabricated green-emissive films display excellent flexibility, uniformity and transparency in the normal and ultraviolet $254 \mathrm{~nm}$ light illumination. Aforementioned results revealed that prepared $\mathrm{NH}_{4} \mathrm{Cl}$ flux assisted $\mathrm{La}_{2} \mathrm{Zr}_{2} \mathrm{O}_{7}: \mathrm{Tb}^{3+}(7 \mathrm{~mol} \%) \mathrm{NPs}$ are considered to be best candidate for multi-dimensional applications.

\section{Introduction}

From past decades, global energy demand has expanded dramatically since the industrial revolution and hence there was a need to develop innovative technologies to meet those demands [1, 2]. To mitigate this issue, artificial light production was one such area where scientists have demonstrated a keen interest in exploring materials and methods for design and develop lower power consumption devices [3, 4]. Rare-earth (RE) ions doped nanophosphors (NPs) were crucial candidates that have been extensively utilized in solid-state lighting, efficient displays with high brightness, excellent luminescence efficiency, and superior energy saving competences owing to their good thermal and chemical stability [5-8]. Generally, partially filled $4 f$ electrons of RE ions shielded by $5 s$ and $5 p$ filled orbitals, due to which $4 f$ electronic transitions were defended by external fields [9]. These $4 f-4 f$ electronic transitions of RE ions result in narrow emissions and a longer lifetime, which make it incomparable with other NPs and henceforth versatile in uses [10].

The photoluminescence $(P L)$ intensity enhancement of the NPs was considered to be major task for research community. In this aspect, several strategies have been developed so far, such as charge compensation, uses of fluxes, creating asymmetry in the crystal field, etc. $[11,12]$ Among them, fluxes are most important in synthesis of the phosphor and thereby improve the optical characteristics of phosphor materials. They serve as a medium for incorporating activators, lowering the firing temperature, and improving the crystallinity of the phosphor [13]. Fluxes, including $\mathrm{NaCl}, \mathrm{KF}, \mathrm{BaF}_{2}, \mathrm{NaF}, \mathrm{LiF}, \mathrm{BaCl}_{2}$, etc. have been demonstrated to have a favourable effect on crystallite size distribution and emission intensity [14-17]. The selection of chemically and thermally stable inorganic host materials, which can hold the dopant ions, effectively was highly necessitate. Till date, several hosts sulfides, silicates, borates, tungstate, molybdates, phosphates, etc. has been extensively studied [18-24]. 
Among them, $\mathrm{A}_{2} \mathrm{~B}_{2} \mathrm{O}_{7}$ type pyrochlores, especially $\mathrm{La}_{2} \mathrm{Zr}_{2} \mathrm{O}_{7}$ (LZO) has recently paid a lot of attention from the materials science community because of their intriguing properties, such as structural flexibility, the ability to accommodate a large number of dopants, high thermal, mechanical, chemical, radiation stability, high oxygen conductivity, high dielectric constant, and so on [25-27]. As a result, LZO pyrochlores were considered as a crucial class of functional materials, which offers wide range of applications, such as renewable energy, catalysis, nuclear waste hosts, scintillators, phosphors, thermal sensors, etc. [28, 29].

Generally, fingerprints (FPs) were traces left on an object's surface when fingers touch it. Because an individual's papillary ridge pattern on each finger was unique and remains unchanging from cradle to grave, they can serve as indisputable proof to prove whether a person was engaged in a given incident [30,31]. In fact, the concept of a "fingerprint" as a unique and permanent identifier was so deeply ingrained that it was frequently used to other means of identification [32]. FPs were divided into two types based on their visibility: latent fingerprints (LFPs) and visible fingerprints. Because LFPs were not directly visible and hence more difficult to erase, they were one of the most common types of physical evidence collected at crime scenes [33,34]. To put it another way, some treatment was required to make them visible enough for identification, and as a result, numerous FPs development procedures based on various chemical, physical, or biological principles have gradually emerged and developed. Due to its ease and broad applicability, the powder method has been the most extensively used approach in crime scene investigation since the early 1900s $[35,36]$. The characteristics of FP powders were a significant component impacting the method's success. Traditional methods, such as metallic powders and magnetic powders have limitations, such as low background interference, poor selective interactions to FP deposits, and offers significant health risks for users [37, 38]. As a result, the development of innovative and high-efficiency FP powders for sensitive LFPs visualization was critical. Till date, the various fluorescent materials were used for visualization of LFPs followed by powder dusting method (Table 1), but their practical use as FP powders was severely limited due to strict synthetic conditions, high cost and relatively weak stability. To overcome from these limitations, luminescent-based materials were more suited for visualization of LFPs in a more straightforward and costeffective manner. 
Table 1

Previous literature of various materials used for visualization of LFPs followed by powder dusting method.

\begin{tabular}{|c|c|c|c|c|c|c|}
\hline $\begin{array}{l}\text { Sl. } \\
\text { No }\end{array}$ & Sample & $\begin{array}{l}\text { Source of } \\
\text { excitation } \\
\text { (nm) }\end{array}$ & Surfaces & $\begin{array}{l}\text { Extracted } \\
\text { ridge } \\
\text { details }\end{array}$ & $\begin{array}{l}\text { Aging } \\
\text { (days) }\end{array}$ & References \\
\hline 1 & $\mathrm{CaTiO}_{3}: \mathrm{Pr}^{3+}$ & 345 & $\begin{array}{l}\text { Holograms, } \\
\text { compact disk }\end{array}$ & Type I-III & - & Swati et al. [39] \\
\hline 2 & $\begin{array}{l}\mathrm{Eu}_{\mathrm{x}} \mathrm{Tb}_{1-\mathrm{x}}(\mathrm{AA})_{3} \\
\text { Phen complexes }\end{array}$ & 312 & $\begin{array}{l}\text { Plastic sheets, } \\
\text { aluminum alloy, } \\
\text { ceramic tiles, } \\
\text { painted wood, } \\
\text { leather and } \\
\text { transparent } \\
\text { glass }\end{array}$ & Type I-III & 90 & Peng et al. [40] \\
\hline 3 & $\begin{array}{l}\mathrm{Y}_{2} \mathrm{O}_{3}: \mathrm{Er}^{3+}, \\
\mathrm{Yb}^{3+} @ \mathrm{SiO}_{2} @ L G d E u x T b_{1-x} \mathrm{H} \\
\text {-PMA }\end{array}$ & 254 & $\begin{array}{l}\text { Glass petri dish, } \\
\text { glass, mouse, } \\
\text { ceramic tile, } \\
\text { knife, wood }\end{array}$ & Type I-II & - & Jun Xu et al. [41] \\
\hline 4 & $\mathrm{Y}_{2} \mathrm{O}_{3}: \mathrm{Eu}^{3+}$ & - & $\begin{array}{l}\text { Aluminum foil, } \\
\text { glass, plastic }\end{array}$ & Type I-II & - & $\begin{array}{l}\text { Askerbay et al. } \\
\text { [42] }\end{array}$ \\
\hline 5 & $\mathrm{CaGdAlO}_{4}: \mathrm{Eu}^{3+}$ & 254 & $\begin{array}{l}\text { Glass, aluminum } \\
\text { foil, compact } \\
\text { disc, stainless } \\
\text { steel, } \\
\text { plastic tube, } \\
\text { compact disc }\end{array}$ & Type I-III & - & Park et al. [43] \\
\hline 6 & $\mathrm{Ba}_{2} \mathrm{LaNbO}_{6}: \mathrm{Mn}^{4+}$ & 365 & $\begin{array}{l}\text { Stainless steel, } \\
\text { aluminum foil, } \\
\text { glass, plastic }\end{array}$ & Type I-III & 5 & Pavitra et al. [44] \\
\hline 7 & $\begin{array}{l}\mathrm{SiO}_{2} @ \mathrm{Y}_{2} \mathrm{O}_{3}: \mathrm{Eu}^{3+}, \mathrm{M}^{+}\left(\mathrm{M}^{+}=\right. \\
\mathrm{Li}, \mathrm{Na}, \mathrm{K})\end{array}$ & 254 & $\begin{array}{l}\text { Bank currency, } \\
\text { papers, pellet die, } \\
\text { steel, textured } \\
\text { marbles, wooden } \\
\text { floor, coin, } \\
\text { compact disk, } \\
\text { glass, credit } \\
\text { cards }\end{array}$ & Type I-III & - & $\begin{array}{l}\text { Venkatachalaiah } \\
\text { et al. [45] }\end{array}$ \\
\hline 8 & $\mathrm{Sr}_{2} \mathrm{MgMoO}_{6}: \mathrm{Eu}^{3+}$ & 395 & Aluminum foil & Type I-III & - & Wang et al. [46] \\
\hline 9 & $\mathrm{CaSn}(\mathrm{OH})_{6}: \mathrm{Eu}^{3+}$ & 254 & $\begin{array}{l}\text { Glass, ceramic, } \\
\text { highlighter, } \\
\text { aluminum foil, } \\
\text { color paper, leaf, } \\
\text { currency }\end{array}$ & Type I-III & 90 & $\begin{array}{l}\text { Ghubish et al. } \\
\text { [47] }\end{array}$ \\
\hline
\end{tabular}




\begin{tabular}{|c|c|c|c|c|c|c|}
\hline $\begin{array}{l}\text { Sl. } \\
\text { No }\end{array}$ & Sample & $\begin{array}{l}\text { Source of } \\
\text { excitation } \\
(\mathrm{nm})\end{array}$ & Surfaces & $\begin{array}{l}\text { Extracted } \\
\text { ridge } \\
\text { details }\end{array}$ & $\begin{array}{l}\text { Aging } \\
\text { (days) }\end{array}$ & References \\
\hline 10 & $\mathrm{MoO}_{3}: \mathrm{Dy}^{3+}$ & Day light & $\begin{array}{l}\text { Stamp pad, } \\
\text { computer } \\
\text { mouse, stainless } \\
\text { steel spatula, } \\
\text { textured marble, } \\
\text { glass and } \\
\text { compact disk }\end{array}$ & Type II & - & $\begin{array}{l}\text { Yogananda et al. } \\
\text { [48] }\end{array}$ \\
\hline 11 & $\mathrm{Y}_{4} \mathrm{Zr}_{3} \mathrm{O}_{12}: \mathrm{Eu}^{3+}$ & 254 & $\begin{array}{l}\text { Glass, aluminum } \\
\text { foil, } \\
\text { compact disc, } \\
\text { steel, plastic, } \\
\text { passport }\end{array}$ & Type I-III & - & Park et al. [49] \\
\hline 12 & AIN:Ce, Tb & - & $\begin{array}{l}\text { Metal, paper, } \\
\text { plastic, steel, } \\
\text { cardboard, } \\
\text { transparent } \\
\text { plastic, bank } \\
\text { card }\end{array}$ & Type I-II & - & Wang et al. [50] \\
\hline 13 & $\mathrm{SnO}_{2}: \mathrm{Eu}^{3+}$ & 254 & $\begin{array}{l}\text { Highlighter, } \\
\text { sprayer, granite, } \\
\text { soft drink can, } \\
\text { leaf }\end{array}$ & Level I-III & 5 & $\begin{array}{l}\text { Deepthi et al. } \\
\text { [51] }\end{array}$ \\
\hline 14 & $\mathrm{CspbBr}_{3}$ & 455 & $\begin{array}{l}\text { Aluminium foil, } \\
\text { ceramic, glass, } \\
\text { paper, } \\
\text { transparent } \\
\text { plastic, wood }\end{array}$ & Level I-II & 14 & Jung et al. [52] \\
\hline 15 & $\mathrm{La}_{2} \mathrm{Zr}_{2} \mathrm{O}_{7}: \mathrm{Tb}^{3+}, \mathrm{NH}_{4} \mathrm{Cl}$ & 254 & $\begin{array}{l}\text { Glass, } \\
\text { aluminium foil, } \\
\text { ceramic, glass, } \\
\text { paper, } \\
\text { transparent } \\
\text { plastic, etc. }\end{array}$ & Level I-III & 24 & Present work \\
\hline
\end{tabular}

From past few decades, counterfeiting of documents, currencies, goods (spanning from computer software, consumer products, pharmaceuticals, electronics, automobiles, etc.) was an organized crime that creates numerous risks in public and private sectors, which intern severely affects the global economy [53-55]. For instance, the international chamber of commerce (ICC) forecasted that, the counterfeiting activity impacted lost growth of $\sim \$ 30-54$ billion for the year 2022. In addition, global brand counterfeiting survey reported that counterfeiting globally would reach more than USD 1.82 trillion [56]. Further, counterfeiting also damages the environment by illegally dispose hazardous chemicals as well as release toxic gases, without following environmental amendments. The covid-19 epidemic was a recent attention-getting incident of forgery i.e., medical grade N95 masks. Normally, they can be considered as gold standard to protect against SARS-cov-2. The counterfeiting of such masks may affect not only for hospitals and medical staffs work directly with covid-19 patients, but also for citizens who inadvertently purchase them. The US Department of Homeland Security made significant efforts to recover counterfeit N95 masks in order to combat counterfeiting $[57,58]$. Anti-counterfeiting 
(AC) efforts were required by use of cutting-edge technology to spot forgeries. The emission profiles of lanthanidedoped luminescent materials were bright and unique, with longer lifetimes and substantial pseudo-stokes shifts [59]. Because of these features, materials scientists were focusing more on luminescent-based security inks. Furthermore, security inks must fulfil significant conditions, such as high stability, economical, easily available, enhanced luminescent intensity, adhesive and viscous nature, superior dispersion and wettability (hydrophobic/hydrophilic nature) $[60,61]$. These features may enhance the printing quality and improved its performance to fight against counterfeiting. The present work aimed at the synthesis of terbium doped $\mathrm{La}_{2} \mathrm{Zr}_{2} \mathrm{O}_{7}$ NPs using a solution combustion route and conjugation with various fluxes. To the best of our knowledge, this is one of the first report to investigate the application of the green emanating enhanced luminescent NPs as a suitable nano-probe for multifaceted applications i.e., LFPs visualization, AC security labels, hydrogels and flexible films.

\section{Materials And Method}

Both undoped and $\mathrm{Tb}^{3+}$ doped (1-11 mol \%) LZO NPs were synthesized using a solution combustion route. All chemicals used in the present study were analytical grade and purchased from Sigma Aldrich Private Ltd. The stoichiometric amounts of Lanthanum nitrate $\left[\mathrm{La}\left(\mathrm{NO}_{3}\right)_{3} \cdot 6 \mathrm{H}_{2} \mathrm{O}(99.9 \%)\right]$, Zirconyl nitrate hydrate $\left[\mathrm{ZrO}\left(\mathrm{NO}_{3}\right)_{2} \cdot \mathrm{XH}_{2} \mathrm{O}\right.$ (99.9\%)] and Terbium (III) nitrate pentahydrate $\left[\mathrm{Tb}\left(\mathrm{NO}_{3}\right)_{3} \cdot 5 \mathrm{H}_{2} \mathrm{O}(99.9 \%)\right]$ were taken in a petri dish containing double distilled water $(\sim 60 \mathrm{ml})$. Subsequently, citric acid $\left[\mathrm{C}_{6} \mathrm{H}_{8} \mathrm{O}_{7}\right]$ was added to the initial precursor solution. The obtained solution was thoroughly dissolved using a magnetic stirrer for $\sim 20 \mathrm{~min}$. The resultant reaction solution was placed in a pre-heated muffle furnace maintained at $\sim 450 \pm 10{ }^{\circ} \mathrm{C}$. After few minutes, reaction solution endured vigorously boiled, consequently dehydrated with elimination of gases, such as nitrogen, carbon dioxide and water vapour followed by formation of the final product. Similarly, experiments were repeated by addition of various fluxes, namely $\mathrm{NaBr}, \mathrm{NH}_{4} \mathrm{~F}$ and $\mathrm{NH}_{4} \mathrm{Cl}$ (1 - 5 wt. \%) into the precursor solution. Finally, the obtained product was calcined at $\sim 800^{\circ} \mathrm{C}$ for $\sim 3 \mathrm{~h}$ and used for further characterizations. The schematic illustration for the synthesis of LZO:Tb ${ }^{3+}(7 \mathrm{~mol} \%)$ NPs blended with various fluxes by solution combustion method was shown in Figure S1 (a).

\subsection{Characterization techniques}

The Shimadzu made powder X-ray diffractometer (PXRD) with monochromatic CuKa radiation was used to study phase purity of the prepared samples. Morphological and particle size analysis was carried out by Hitachi-3000 table top scanning electron microscope (SEM) and Hitachi H-8100 transmission electron microscope (TEM) provided with $\mathrm{a} \mathrm{LaB}_{6}$ filament equipped with EDS (Kevex sigma TM Quasar, USA). Perkin Elmer Spectrometer (Spectrum 1000) with KBr pellets was used to perform fourier IR reflectance (FTIR) of the prepared NPs. The Perkin Elmer spectrophotometer (Lambda -35) was used to study the diffuse reflectance (DR) of the samples. PL studies were performed with Horiba (Jobin Yuvon) spectrofluorimeter maintained at slit width of $5 \mathrm{~nm}$ with xenon as an excitation source. The Nikon D3100/AF-S digital camera was used to capture developed LFP images and AC labels under normal and UV $254 \mathrm{~nm}$ illumination.

\subsection{Development and visualization of LFPs using optimized La 2 $\mathrm{Zr}_{2} \mathrm{O}_{7}: \mathrm{Tb}^{3+}$ (7 mol \%) (LZOT), $\mathrm{NH}_{4} \mathrm{Cl}$ (4 wt \%) NPs}


Fresh fingerprints (FPs) from different healthy donors were collected by washed their hands several times with hand wash and water, subsequently dried in a normal air. The thumb finger was rubbed slightly against the forehead and impressed on various substrates with minimal pressure for $\sim 3$ to $4 \mathrm{sec}$. The developed FPs were invisible to naked eyes and hence it called as latent FPs (LFPs). To make them visible, the optimized LZOT: $\mathrm{NH}_{4} \mathrm{Cl}$ (4 wt. \%) NPs was stained on the LFPs followed by simple powder dusting technique. The excess powder on the LFPs was removed by smooth to and fro brushing. Finally, the developed FPs were photographed in a digital camera under UV $254 \mathrm{~nm}$ light irradiation. The schematic illustration showing LFPs development and its visualization using prepared NPs followed by conventional powder dusting method was shown in Figure S1 (b).

\section{Abrasion Tests}

Physical abrasion (PA) test was executed by mounting double-sided adhesive tape onto the FP surface and subsequently peeled off (up to 5 cycles). However, chemical abrasions (CA) were performed by treating the developed FP with solvents, namely acetone and toluene for $15 \mathrm{~min}$, and photographed under UV $254 \mathrm{~nm}$ light illumination.

\subsection{Fabrication of security ink using LZOT: $\mathrm{NH}_{4} \mathrm{Cl}(4 \mathrm{wt}$ \%) NPs}

The viscous and luminescent security ink was fabricated using LZOT: $\mathrm{NH}_{4} \mathrm{Cl}$ (4 wt. \%) NPs as follows; the stoichiometric amount of the prepared NPs was thoroughly mixed in a ratio of 85:15 v:v ethanol-water solution (1:9 v:v ethanol:water):glycerol for attain dynamic viscosity. Further, sodium dodecyl sulfonate (3 mg/l) was then added into the above mixture to control the surface tension of the ink. The resulting mixture was ultrasonicated for $\sim 20$ min to achieve transparent ink. The prepared ink was used to design AC patterns on various surfaces followed by simple dip pen method. The encoded patterns were in situ photographed under normal as well as UV $254 \mathrm{~nm}$ light irradiation.

\section{Screen printing}

Screen printing was performed using a mesh with different designs. The prepared inks were poured slowly on the mesh openings and were transferred onto the substrate during the squeezer. Schematic representation of the data encryption and decoding procedure developed by screen printing technique using prepared NPs as a security ink was depicted in Figure S1 (c).

\subsection{Preparation of luminescent hydrogels and flexible films}

Firstly, PVA (4 g) was well dissolved in deionized water $(\sim 30 \mathrm{ml})$ using a magnetic stirrer for $\sim 10 \mathrm{~min}$. Subsequently, formerly prepared luminescent ink $(\sim 10 \mathrm{ml})$ was added slowly into the PVA solution and treated with ultrasonically by inserting titanium probe sonicator for $\sim 15 \mathrm{~min}$ to achieve uniform solution. Finally, the obtained viscous gel was transferred to specific moulds as well as petri plate; allowed to dried for $\sim 48 \mathrm{hrs}$. Later, the obtained patterns and films were photographed using camera under normal and UV $254 \mathrm{~nm}$ light.

\section{Results And Discussion}

Figure 1(a) shows the PXRD profiles of pure and LZO:Tb ${ }^{3+}(1-9 \mathrm{~mol} \%)$ NPs. Sharp and intense diffraction profiles were indexed to a cubic pyrochlore type structure and well matched with JCPDS No.:78-1292 [62]. No additional 
impurity/dopant peaks were identified indicating that dopant $\mathrm{Tb}^{3+}$ ions were effectively substituted in the LZO sites. This was further validated by estimating the acceptable percentage difference between dopant $\mathrm{Tb}^{3+}$ ions in the LZO lattice site using following relation [63];

$$
\Delta_{r}=\frac{R_{m}(C N)-R_{d}(C N)}{R_{m}(C N)} \times 100
$$

where, $\Delta_{r}$ acceptable percentage difference, $R_{m}$; ionic radii of host ions $\left(\mathrm{R}_{\mathrm{La}}=1.16 \AA\right.$, $\left.\mathrm{R}_{\mathrm{Zr}}=0.84 \AA\right)$ and $R_{d}$; ionic radii of dopant ions $\left(\mathrm{R}_{\mathrm{Tb}}=1.04 \AA\right)$ in 8- coordinated system. In the present work, the $\Delta_{r}$ value between $\mathrm{La}^{3+}$ and $\mathrm{Tb}^{3+}$ was found to be $\sim 10.34 \%$ (<30\%), however $\Delta_{r}$ among $\mathrm{Zr}^{4+}$ and $\mathrm{Tb}^{3+}$ was obtained to be $\sim-23.80 \%(<30 \%)$. The obtained $\Delta_{\mathrm{r}}$ value between $\mathrm{La}^{3+}$ and $\mathrm{Tb}^{3+}$ were found to less than acceptable value and it signifying effective occupancy of the $\mathrm{Tb}^{3+}$ ions in the $\mathrm{La}^{3+}$ site of the $\mathrm{LZO}$ lattice rather than $\mathrm{Zr}^{4+}$ site. This might be due to dissimilarity in the charge, size and negative $\Delta_{\mathrm{r}}$ value between $\mathrm{Tb}^{3+}$ ions and $\mathrm{Zr}^{4+}$ site.

In general, fluxes were most significant role in fabrication of the NPs, in particular reduce the firing temperature, improve the crystallinity as well as enhance the optical and luminescence properties. Hence, to realize the role of various fluxes on crystallinity of the prepared $\mathrm{NPs}$, we have utilized different amount of $\mathrm{NaBr}\left(1 \mathrm{wt}\right.$. \%), $\mathrm{NH}_{4} \mathrm{~F}(1 \mathrm{wt}$. $\%)$ and $\mathrm{NH}_{4} \mathrm{Cl}$ (1-5 wt. \%) fluxes assisted NPs. PXRD patterns of the LZOT NPs synthesized using all the above fluxes was shown in Figure 1(b). It was evident that, all the diffraction profiles were well assigned to standard cubic pyrochlore structure (JCPDS No.:78-1292). In addition to this, no obvious peaks belong to fluxes were revealed. The addition of $1 \mathrm{wt}$. \% of $\mathrm{NaBr}, \mathrm{NH}_{4} \mathrm{~F}$ and $\mathrm{NH}_{4} \mathrm{Cl}$ fluxes upsurges the diffraction profile intensities as compared to LZOT NPS. The improvement in the crystallinity after addition of fluxes were due to several factors, namely solubility, melting point, its decomposition property, intermediate compound formation, etc. [64]. Among these fluxes, $\mathrm{NH}_{4} \mathrm{Cl}$ exhibit improved crystallinity. This was mainly attributed to probable reaction between $\mathrm{NH}_{4} \mathrm{Cl}$ with metal nitrate to form ammonium nitrate. Here, ammonium nitrate plays dual role; (i) combustible material and (ii) oxidizing agent - assist other materials to burn. Hence, the exothermicity of the redox reaction during synthesis was anticipated to be very high, and also provide the molten medium for mixing of fuel and oxidant as a result enhancement in the crystallinity $[65,66]$. However, in the case of $\mathrm{NaBr}$ and $\mathrm{NH}_{4} \mathrm{~F}$ assisted samples have very low solubility as well as very high melting point result in no significant changes in the crystallinity when compared to $\mathrm{NH}_{4} \mathrm{Cl}$. Based on the obtained results, LZOT NPs with different amount (1-5 wt. \%) of $\mathrm{NH}_{4} \mathrm{Cl}$ was studied and shown in Figure 1(b). As evident from the figure, highest crystallinity was achieved for 4 wt. \% of $\mathrm{NH}_{4} \mathrm{Cl}$. $\mathrm{The}$ Williamson-Hall $(\mathrm{W}-\mathrm{H})$ plots of the prepared NPs were depicted in the Figure $1(\mathrm{c} \& \mathrm{~d})$. The mean crystallite size of the prepared NPs was calculated using Scherrer's relation and W-H plots [67]. The obtained mean crystallite size and strain were tabulated in Table S1. From the table, the variation in the estimated crystallite size from Scherrer's relation and $\mathrm{W}-\mathrm{H}$ plots was mainly due to negligence of strain component in the Scherrer's, however it considered in the W-H plots. FT-IR spectra of LZO, LZO:Tb ${ }^{3+}$ (1-9 mol \%) NPs and LZOT: NaBr, $\mathrm{NH}_{4} \mathrm{~F}$ and $\mathrm{NH}_{4} \mathrm{Cl}(1 \mathrm{wt}$. \%) fluxes recorded in the range $400-4000 \mathrm{~cm}^{-1}$ was shown in Figure 1(e). The spectra consist of a broad absorbance band centered at $\sim 3410 \mathrm{~cm}^{-1}$, which ascribed water molecules adsorption via O-H stretching vibrations. The bands at $\sim$ 2986 and $2356 \mathrm{~cm}^{-1}$ were due to $\mathrm{C}-\mathrm{H}$ and $\mathrm{O}=\mathrm{C}=\mathrm{O}$ stretching mode, respectively [68]. Band at $\sim 1770 \mathrm{~cm}^{-1}$ representing the presence of $C=0$. Further, a broad band at $\sim 1150-1490 \mathrm{~cm}^{-1}$ represents the stretching vibration of 
tetrahedral group La-O and band at $\sim 564 \mathrm{~cm}^{-1}$ to the Zr-O vibrations [69]. Figure S2 (a \& b) represents the DR spectra of LZO:Tb ${ }^{3+}$ (1-9 mol \%) NPs and LZOT:NaBr, NH${ }_{4} \mathrm{~F}\left(1 \mathrm{wt}\right.$. \%) and $\mathrm{NH}_{4} \mathrm{Cl}$ (1 \& 4 wt. \%) fluxes. The spectra exhibit sharp absorption peaks in the range $\sim 200-300 \mathrm{~nm}$, which ascribed to $4 f \rightarrow 5 d$ electronic transitions of $\mathrm{Tb}^{3+}$ ions [70]. The Kubelka-Munk (K-M) function was utilized to determine energy band-gap $\left(E_{g}\right)$ values of the prepared NPs, as described in the previous literature [71]. The $\mathrm{E}_{\mathrm{g}}$ plots of the LZO:Tb ${ }^{3+}(1-9 \mathrm{~mol} \%)$ NPs and fluxes assisted LZOT NPs was depicted in Figure 1 ( $f$ ). As evident from the figure, the $E_{g}$ values were estimated and found to be 3.47-3.49 eV (Table S1). SEM images of pure and LZO:Tb ${ }^{3+}$ (1-9 mol \%) NPs was shown in Figure S3 (a-f). As evident from the figure, the particles were found to irregular, porous and flaky-like morphology. The observed porous nature which mainly ascribed to uniform combustion as well as movement of flame distribution throughout the combustion process. These features were inherent nature of the combustion synthesis. After addition of the fluxes in aqueous medium, the flaky-like structure was clearly retained (Figure S3 (g-i)). This was mainly attributed to its excellent solubility, which uniformly distributes and it offers the medium for homogeneous distribution of fuel. Figure S3 (j \& k) depicts the TEM, images of the LZOT NPs and LZOT: $\mathrm{NH}_{4} \mathrm{Cl}(4$ wt. \%) NPs. As observed from the TEM image, particles were agglomerated and their average size was found to be $\sim 12 \mathrm{~nm}$. The interplanar spacing was estimated from the HRTEM image (Figure S3 (I)) and the value was obtained to be 0.312 $\mathrm{nm}$ for (222) plane. The high crystallinity of the optimized NPs was further confirmed from the selected area of electron diffraction (SAED) pattern (inset of Figure S3 (I)).

Figure 2(a) depicts the PL excitation spectrum of LZOT NPs by monitoring $546 \mathrm{~nm}$ emission wavelength at room temperature. The spectrum reveals several well resolved intense peaks at $\sim 317,328,339,351,377,396$ and 489 nm owing to ${ }^{7} \mathrm{~F}_{6} \diamond^{5} \mathrm{D}_{0},{ }^{7} \mathrm{~F}_{6} \diamond^{5} \mathrm{D}_{1},{ }^{7} \mathrm{~F}_{6} \diamond^{5} \mathrm{~L}_{6},{ }^{7} \mathrm{~F}_{6} \diamond^{5} \mathrm{~L}_{9},{ }^{7} \mathrm{~F}_{6} \diamond^{5} \mathrm{G}_{6},{ }^{7} \mathrm{~F}_{6} \diamond^{5} \mathrm{D}_{3}$ and ${ }^{7} \mathrm{~F}_{6} \diamond^{5} \mathrm{D}_{4}$ transitions of $\mathrm{Tb}^{3+}$ ions, respectively [72]. Among them, intensity of the excitation peak was maximum at $\sim 377 \mathrm{~nm}$, in which efficient energy may transfers from the host to the $\mathrm{Tb}^{3+}$ ions and it can be being approximately equivalent for traditional NUV LED chips. PL emission spectra of LZO:Tb ${ }^{3+}(1-9 \mathrm{~mol} \%)$ NPs excited at $~ 377 \mathrm{~nm}$ wavelength was shown in Figure 2(b). The spectra comprised with characteristic emission peaks originated from the ${ }^{5} D_{3}$ and ${ }^{5} D_{4}$ energy levels to various ${ }^{7} \mathrm{~F}_{\mathrm{J}}(\mathrm{J}=3,4,5,6)$ levels. The peaks centered at $\sim 416,439$, and $466 \mathrm{~nm}$, which ascribed to ${ }^{5} D_{3} \diamond^{7} F_{5},{ }^{5} D_{3} \diamond^{7} F_{4}$ and ${ }^{5} D_{3} \diamond^{7} F_{3}$ transitions of the $T b^{3+}$ ions, respectively. However, emission peaks at $\sim 491,546$, 587 and $622 \mathrm{~nm}$ arises from ${ }^{5} \mathrm{D}_{4} \diamond^{7} \mathrm{~F}_{\mathrm{J}}(\mathrm{J}=6,5,4,3)$ transitions of $\mathrm{Tb}^{3+}$ ions, respectively [73]. Among these, a peak at $\sim 546$ was accountable for bright green emission of doped $\mathrm{Tb}^{3+}$ ions. It was evident from the figure that, emission originated from the ${ }^{5} D_{4} \diamond^{7} F_{J}$ transitions were more prominent than the ${ }^{5} D_{3} \diamond^{7} F_{J}$ transitions. This might be attributed to cross-relaxation among $\mathrm{Tb}^{3+}$ ions, which can be expressed as below [74];

\section{$T b^{3+}\left({ }^{5} D_{3}\right)+T b^{3+}\left({ }^{7} F_{6}\right) \rightarrow T b^{3+}\left({ }^{5} D_{4}\right)+T b^{3+}\left({ }^{7} F_{0}\right)-------------(2)$}

Electrons in ${ }^{5} \mathrm{D}_{3}$ state get relaxed at ${ }^{5} \mathrm{D}_{4}$ and the ${ }^{7} \mathrm{~F}_{6}$ electrons of $\mathrm{Tb}^{3+}$ ions excited to ${ }^{7} \mathrm{~F}_{0}$ state. This process declines ${ }^{5} D_{3} \diamond^{7} F_{J}$ transitions, while ${ }^{5} D_{4} \diamond^{7} F_{J}$ transitions becomes more dominated. As a result, the present NPs shows diminished bluish-green emission (400-470 nm) and intense green emission (480-630 nm). Energy level diagram of $\mathrm{Tb}^{3+}$ ions doped LZO NPs representing probable excitation and emission transitions were depicted in Figure S4. Normally, dopant concentration in the phosphors will influence the emission performance. In the present work, the emission intensity increases with increase of $\mathrm{Tb}^{3+}$ concentration up to $7 \mathrm{~mol} \%$ and subsequently it 
declines with further increase of dopant concentration was noticed (Figure 2(c)). This was mainly attributed to conventional concentration quenching phenomena, which provide a clear insight for non-radiative energy relaxation process between nearby $\mathrm{Tb}^{3+}$ ions. The critical distance $\left(R_{c}\right)$ between the $\mathrm{Tb}^{3+}$ ions in the present NPs was estimated using following relation [75];

$$
R c=2\left(\frac{3 V}{4 \pi X_{c} N}\right)^{1 / 3}
$$

where, $V$; unit cell volume $\left(1254.04 \AA^{3}\right), X_{\dot{c}}$ critical concentration $(0.07)$, and $N$; number of lattice sites in crystallographic unit cell available for dopant ions (8). In the present work, the value of $R_{C}$ was estimated and found to be $\sim 8.1 \AA$. The obtained $R_{C}$ value (> $5 \AA$ ) which over rule the probability of exchange interaction. Further, no spectral overlap was clearly observed, indicating the occurrence of radiative re-absorption mechanism. Hence, it was clearly demonstrated that the energy transfer mechanism was directed through multipole-multipole interactions. According to Dexter's theory, type of multipolar interaction responsible for concentration quenching was elucidated by using following equation [76];

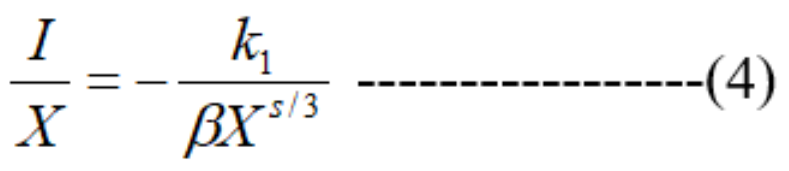

here, $X$; dopant concentration, $k_{1}$ and $\beta$; constants for each interaction in the same excitation conditions for a given host lattice, and $s$, series of the electric multipolar interactions (dipole-dipole $(d-d)$, dipole-quadrupole $(d-q)$ and quadrupole-quadrupole $(q-q)$ when the values of $s$ are 6,8 and 10, respectively). The value of $s$ can be calculated from the slope $(s / 3)$ of the linear fitted line in Figure $2(\mathrm{~d})$, which plots $\log (I / X)$ versus log $X$ on a logarithmic scale of $I / X$. The value of $(-s / 3)$ was found to be -1.889 . Thus, the value of $s$ can be calculated as $\sim 6.81$ (close to the theoretical value 6 for the electric $d-d$ interaction), which signify that the $d-d$ interaction was the main mechanism for the concentration quenching of $\mathrm{Tb}^{3+}$ ions in the LZO host. The effect of fluxes on the emission intensity of LZOT NPs was studied and depicted in Figure 2(e). Identical profiles in the emission was clearly noticed in the without and with flux assisted NPs. Further, the enhancement in the PL emission intensity was achieved for flux (1 wt. \%) assisted NPs when compared to without flux. This may have attributed to increase in crystallinity and phase purity, which will reduce the lattice and surface defects of the NPs. Among the fluxes, PL emission was higher (2-fold) in the $\mathrm{NH}_{4} \mathrm{Cl}$ assisted NPs when compared to the $\mathrm{NH}_{4} \mathrm{~F}$ and $\mathrm{NaBr}$ for 1 wt. \%. However, influence of different $\mathrm{NH}_{4} \mathrm{Cl}$ amount (1-5 wt. \%) on the PL emission intensity was examined (Figure 2(f)). As evident from the figure, $\mathrm{PL}$ intensity increases with increase of the $\mathrm{NH}_{4} \mathrm{Cl}$ amount up to 4 wt. \% and later diminishes. The noticed decrement in the PL intensity with further addition of the flux was mainly ascribed to the substitution of chlorine ions for oxygen ions in the host lattices. Aforementioned results clearly demonstrated that the $\mathrm{NH}_{4} \mathrm{Cl}$ assisted NPs improves the crystallinity, which intern an enhancement of the PL emission.

To evaluate the color quality and performance of the prepared NPs in color space, CIE 1931 chromaticity diagram was used for identifying the emission color of the prepared NPs for solid state lighting applications [77]. The CIE 
color co-ordinates $(x, y)$ were estimated using the PL emission of the prepared NPs. The $(x, y)$ co-ordinate values were denoted by different symbols in the CIE diagram (Figure 3 (a \& c)). The estimated CIE color co-ordinates of the NPs located near to those of EBU (European Broadcasting Union for green illumination, $(x, y=0.29,0.60)$ ), which showcase the significance of the $\mathrm{NH}_{4} \mathrm{Cl}$ assisted LZOT NPs as a green component in the WLEDs. In addition, correlated color temperature (CCT) was also considered as important parameter to evaluate the color quality of the NPs. In the present work, CCT of the prepared NPs without and with fluxes were estimated using following expression [78];

\section{$C C T=-437 n^{3}+3601 n^{2}-6861 n+5514.31--------------(5)$}

where, $n=\left(\mathrm{x}-\mathrm{x}_{\mathrm{e}}\right) /\left(\mathrm{y}-\mathrm{y}_{\mathrm{e}}\right) ; \mathrm{x}, \mathrm{y}$ are the color co-ordinates of sample and $\mathrm{x}_{\mathrm{e}}, \mathrm{y}_{\mathrm{e}}$ are chromaticity epicenter $\left(\mathrm{x}_{\mathrm{e}}=0.3320\right.$, $\left.y_{e}=0.1858\right)$. The CCT diagram of the prepared NPs was depicted in the Figure 3 ( $\left.b \& d\right)$. The estimated CCT values found to be in the range $\sim 5200-7000 \mathrm{~K}$, which were fairly equivalent to commercial WLEDs. Hence, the optimized $\mathrm{NH}_{4} \mathrm{Cl}$ assisted LZOT NPs may play a significant role in UV excited cool WLEDs. Further, color purity of the phosphors was considered as an attractive feature which reveals their applicability for plentiful applications. In the present work, the color purity of the prepared NPs was estimated using the following relation [79];

$$
\text { Color purity }=\frac{\sqrt{\left(x-x_{e e}\right)^{2}+\left(y-y_{e e}\right)^{2}}}{\sqrt{\left(x_{d}-x_{e e}\right)^{2}+\left(y_{d}-y_{e e}\right)^{2}}} \times 100 \%
$$

where $(x, y)$; co-ordinates of a sample point, $\left(x_{d}, y_{d}\right)$; co-ordinates of the dominant wavelength and $\left(x_{e e} y_{e e}\right)$; coordinates of the illuminate point. The estimated color purity of the optimized NPs was found to be $\sim 97 \%$. The estimated photometric properties of the prepared NPs were listed in Table S2. The estimated photometric properties of the prepared NPs were found to be well acceptable as compared to previous literatures (Table S3). The obtained values reveal that the prepared NPs was considered to be excellent candidate for green color dominance in the UV excited WLEDs.

\section{Applications Prospect}

\subsection{Visualization of LFPs using LZOT: $\mathrm{NH}_{4} \mathrm{Cl}$ (4 wt. \%) NPs}

Due to the excellent solid-state PL performance of the prepared NPs, it was used to strengthen its application capability for various fields, especially in forensic science. To explore the practicality of the optimized LZOT: $\mathrm{NH}_{4} \mathrm{Cl}$ (4 wt. \%) NPs, we adopted powder dusting approach for the visualization of LFPs on various substrates. Figure 4(a-d) shows the visualized FPs using prepared NPs on non-porous surfaces (compact disc, metal scale, glass and mobile phone screen) under UV $254 \mathrm{~nm}$ light illumination. As evident from the figure, the developed FPs with distinguishable ridge details (level I-III) were clearly visible, due to the strong adhesion of the NPs with chemical constituents present in the LFPs. Normally, chemistry of LFPs residue was more complicate, due to comprise of several chemical constituents. These components readily form a complex matrix, an emulsion of water, organic and inorganic compounds $[99,100]$. The chemical residues present in the LFPs were normally very minimal (less than $10 \mu \mathrm{g}$ ) with average thickness of about $0.1 \mu \mathrm{m}$. The LFPs were impressed on the surfaces, nearly $99 \%$ of the 
LFPs contains water [101]. As this water begins to evaporate quickly from the LFPs, subsequently the FPs dried. This process begins to modify certain powders ability to visualize the such FPs. Hence, LFPs dusting powder with specific functional groups which interacts with FP residues for improve the visualization ability were highly necessitate. In the present work, $\mathrm{NH}_{4} \mathrm{Cl}$ (4 wt. \%) flux assisted NPs can readily interact with water soluble FPs components typically composed of amino acids (especially serine). Since serine was the most abundant amino acid present in the FPs as compared to other constituents. However, detection sensitivity of the optimized NPs for LFPs visualization on various porous surfaces, including wood, paper, ticket and tissue paper (Figure 4(e-h)) and semi-porous surfaces, namely glossy paper, plastic card, aluminium foil and cardboard sheet (Figure 4(i-I)) under UV $254 \mathrm{~nm}$ light irradiation were examined. It was clear from the figure, well-defined ridge features enabling up to level- I \& II details with high sensitivity, low contrast and without any background hindrance. The gray scale pixel profiles of marked yellow box on the developed FPs (Figure 4(m-o)) revealed that prepared NPs were clearly stacked exactly on the ridges rather than furrows due to its nano regime and better adhesive nature. It also supports the above result, in which green value was visibly high for the ridge regions, however minimal for the furrow regions. Further, 3D interactive plots of the developed FPs also evidenced that the stained NPs was uniformly distributed over the surface of the LFPs (Figure 4(p-r)).

Generally, ridges as well as valleys are the most significant characteristics of the FPs. These characteristics were normally categorized into three levels [102]. They are, level-I features are the vein feature of the FPs, which comprise of central point, delta, whorl, loop and arch, which were not enough for personal individualization. Furthermore, level-II features are macroscopic, involving ridge dot, termination, lake, island, bifurcation, fold of the ridge and rift valley of the furrow. In addition, level-III features were microscopic characteristics, such as sweat pores, length of the ridge, ridge width, shape of the ridge end, shapes and sizes of the sweat pores, successive distance between pores, scars, ridge bifurcation angle, etc. $[103,104]$. These features are most significant in forensic investigation but fails to develop and analyse in detail due to inability of the conventional powders under different circumstances. This makes us to motivate to develop efficient NPs, which can enable level-III features in detail. Figure 5(A \& B) represents developed FPs of the two different donors stained with $\mathrm{NH}_{4} \mathrm{Cl}(4 \mathrm{wt}$. \%) flux assisted LZOT NPs on glass substrate under UV $254 \mathrm{~nm}$ light illumination. It was clearly noticed from the figure that, the NPs adhered well with FPs, showing green emission in the ridgeline, but black in the groove region under UV irradiation. The level-I features, such as whorl, loop, delta and center dot were clearly revealed. In addition, levelII features, like bifurcation, ridge end, dot, enclosure, bridges, hook, cross over, lake, termination, etc. which were the clearly explored (Figure S5). Furthermore, most authenticated level-III features of the FPs of the two different donors, which enclosing all dimensional properties of the ridges were revealed and tabulated in Table 2. As evident from the table, level-IIl dimensionality was varied with donors, which clearly support the statement "no two persons have ever been found to have the same fingerprints". In addition, SEM images of the developed FPs, also revealing positions of the sweat pores, distance between successive pores, bifurcation and hook angle, shape of the ridge end, width of the ridges, ridge end angle details, etc. (Figure 5(c - j).

The chemical residues of the FPs vary over the time after deposition, which depends on various factors, such as atmospheric contamination, humidity, light exposure, temperature, ultraviolet and other radiations, etc. In the present work, series of experiments were performed to investigate influence of external PA on the developed FPs on the glass surface under UV 254 nm illumination (Figure 6 (a-f)). The photographed images clearly revealed that the FPs were scratched to some degree, however, sufficient ridge features required for personal individualization can be clearly enabled even up to 5 cycles of PA. Pixel profiles and 3D interactive plot of the developed FPs before and after PA, showing that the NPs were uniformly distributed and stacked on the ridges rather than furrow region

Page 12/34 
(Figure 6(g-i)). Likewise, CA test was also accomplished by soaking the LFPs on the glass surface with acetone and toluene and developed using the optimized NPs (Figure 6 (j, j', k \& k'). No disruptive interference and clear ridge details can be clearly observed even after chemical treatment. The developed FPs before and after CA were exhibit almost similar emission without any disruption. The obtained results substantially demonstrated that the present strategy was more efficient in visualizing LFPs with insignificant effect of powerful external intrusions. The corresponding pixel profiles were clearly demonstrated that the NPs effectively interact with amino acids present in the ridge region rather than furrow portions (Figure 6(I)). Further, exposure of light on developed FPs can significantly affect FPs compositions. Herein, photo-stability of the developed FPs on the glass upon continuous UV $254 \mathrm{~nm}$ (Figure 6(m-r)) and $365 \mathrm{~nm}$ illumination (Figure 6(s-x)) up to $\sim 6 \mathrm{~h}$ was examined. Well-defined ridge features, which reveal level I-III details without any noticeable luminescence quenching was noticed. This signifying that UV exposure will not much influence on the visualization ability of the prepared NPs. To evaluate the practicality of the NPs for the visualization of LFPs, we performed the FPs development trials after various FPs aging time (up to 24 days). As displayed in Figure 7(a-e), the gradual decrement in the visualization sensitivity with extended aging was noticed, which ascribed to slow evaporation of the FPs residue over the time. Moreover, LFPs aged for up to 24 days can reveal clear ridges including level I-III features, signifying that the sensitivity of the present NPs was high enough for visualization of aged FPs. Further, pixel profile value shows greater contrast between fluorescent dark and bright field furrow (Figure $7(f-j)$ ). The obtained results were well validated from corresponding 3D interactive plots (Figure 7(k-0)).

\subsection{Anti-counterfeiting applications}

The enhanced PL property of the prepared LZOT: $\mathrm{NH}_{4} \mathrm{Cl}$ (4 wt. \%) NPs, which opens up new avenue for practical AC applications. Over the decades, forging/duplicity of important goods or documents, namely certificates, currency, big-name brands, medicines, foods, etc. are serious threat all over the world that causes a severe negative impact on the human health, world economy and social development [105-108]. To combat this issue, several fluorescent based materials have been used for AC applications, nevertheless, the luminescence quenching, spectral overlap, low quantum efficiency and toxicity remains a major concern [109]. In this context, we fabricated luminescent based security inks to authenticate the practicability of the prepared NPs for AC applications. The prepared ink was used in screen printing technology to establish the AC patterns (trees and ice cream) on the paper surface under normal light (Figure 8(a-c) and UV $254 \mathrm{~nm}$ light illumination (Figure 8(a'-c')). The designed patterns were invisible to the naked eye under normal light, while distinctive and sharp luminescence patterns were decoded under UV $254 \mathrm{~nm}$ light. However, to make the process simplify and cost effective, we directly designed different patterns by a pen filled with prepared ink. Figure 8(d-i) display the AC labels on various surfaces (such as plastic, transparent polyethylene sheet (used for commercial packaging), filter paper, ceramic tile, aluminium foil and foam) by employing simple dip pen technique under normal (Figure 8(d-i)) and UV 254 nm light illumination (Figure 8(d'-1')). It was very clear from the figure that, designed AC patterns were invisible under normal light, however corresponding distinctive patterns were decoded upon UV $254 \mathrm{~nm}$ light illumination. The obtained results signify that surfaces will not affect the designed patterns. Hence, prepared flux assisted NPs opens wide scope in AC applications, especially signature or personalized security information. Further, photostability, durability and mechanical stability of the designed patterns were examined. The AC patterns on the paper surface was continuously illuminated with UV $254 \mathrm{~nm}$ for different time periods (1-5 h) (Figure S6). The obtained results clear showed that intensity of the green emission was almost retained even after $5 \mathrm{hr}$ prolonged illumination. However, durability of the patterns on the ceramic tile was examined by varying temperature from $32,40,50,60$ and $70{ }^{\circ} \mathrm{C}$

Page 13/34 
(Figure S7), which clearly demonstrated that the marginal intensity loss was noticed. The mechanical stability of AC patterns on the aluminium foil was also examined by ultrasonication for 10-50 min at $30 \mathrm{kHz}$ (Figure S8). The decorated AC patterns on transparent polyethylene sheets retain its luminescence intensity even after sonication in water, which authenticated to the stability of the prepared ink. Flexible luminescent hydrogels were highly proficient in converting absorbed energy (like current, electric field, biologic processes, X-ray, chemical reaction, etc.) into electromagnetic radiation $[110,111]$. They can be extensively used in various applications, such as optoelectronics devices, field-effect transistors, detectors, medical diagnosis, bio-imaging, etc. [112-114]. Hence, luminescent gels have been paid much attention due to their outstanding biocompatibility and viscoelastic properties [115]. Herein, luminescent hydrogels with excellent luminescence were fabricated and used for AC applications. The information was encrypted in various scrambled patterns and photographed under normal (Figure 8(j-I)) and UV $254 \mathrm{~nm}$ light (Figure $8\left(j^{\prime}-l^{\prime}\right)$ ). These encrypted information was decoded by displaying green emission and hidden information can be realized clearly under UV light as "BUS, SUB, US" and "DIGITAL INDIA". The. Further, flexible luminescent films were most commonly used as a labels, packaging, displays, etc., which influenced significant application value in industries as well as life. The prepared films exhibit uniformity and transparency in the visible light Figure $8\left(\mathrm{~m} \& \mathrm{~m}^{\prime}\right)$. Further, the luminescent film was highly flexible, and it offers maximum deformation of $200 \%$. Simultaneously, However, the films with green emission under UV $254 \mathrm{~nm}$ was also retained its transparent nature (Figure 8(n, n', o, o'). As can be seen from the figure, no variations in the luminescence intensity with increase of stretching, which might be due to stable in the material density with increase of surface area.

\section{Conclusion}

A low cost and effective method has been developed for the synthesis of Tb3+ (1-11 mol \%) doped LZO NPs by conjugating the fluxes via simple solution combustion route. Sharp and intense PXRD profiles were indexed to a cubic pyrochlore type structure. The improvement in the crystallinity after addition of $\mathrm{NH}_{4} \mathrm{Cl}$ fluxes exhibit improved crystallinity, which mainly attributed to probable reaction between $\mathrm{NH}_{4} \mathrm{Cl}$ with metal nitrate to form ammonium nitrate. The PL emission intensity increases with increase of $\mathrm{Tb}^{3+}$ concentration up to $7 \mathrm{~mol} \%$ and subsequently it declines due to conventional concentration quenching. PL emission was found to be higher (2fold) in the $\mathrm{NH}_{4} \mathrm{Cl}$ assisted NPs when compared to the $\mathrm{NH}_{4} \mathrm{~F}$ and $\mathrm{NaBr}$ for 1 wt. \%. The estimated CIE color coordinates of the NPs located near to those of European Broadcasting Union for green illumination (EBU, $(x, y=0.29$, 0.60)), which showcase the significance of the $\mathrm{NH}_{4} \mathrm{Cl}$ assisted LZOT NPs as a green component in the WLEDs. The estimated CCT values found to be in the range $~ 5000-7000 \mathrm{~K}$, which were fairly equivalent to commercial WLEDs. These obtained colorimetric parameters of the NPs which endorse its usage in high-contrast imaging applications, especially to overcome auto fluorescent backgrounds. Well-defined ridge features enabling up to level- I-III details with high sensitivity, low contrast and without any background hindrance were revealed using optimized NPs. The developed films show high photostability against UV irradiation, longer durability and highly flexible. The prepared hydrogels were used to encrypt the information and these encrypted information was decoded by displaying green emission as "BUS, SUB, US" and "DIGITAL INDIA" under UV 254 nm light. To the best of our knowledge, the present work delivers a smart alternative approach on fabricating highly luminescence NPs for various labelling FPs, luminescent security patterning and flexible films applications.

\section{Declarations}

\section{Acknowledgment:}


The author (H. N.) acknowledge VGST, Govt. of Karnataka, India [VGST/KFIST-4/GRD-489] for sanction of the project. The author H. B. P also grateful to DST (SERB), Govt. of India [CRG/2020/006446] and management of MS Ramaiah University of Applied Sciences for constant support.

\section{Authors Contribution:}

The authors G.P.D and H.N are contributed equally to this work. D.R.L and J.M. designed and synthesized the samples; H.B.P performed the scanning electron microscopy, X-ray diffraction, photoluminescent spectroscopy measurements; H.A performed fingerprints experiments and pixel profile modelling; G.P.D wrote the manuscript and analysed the data. S.C.S and H. N supervision and editing of the manuscript.

\section{Statement of Authors and Informed Consent.}

The authors confirmed that all experiments (taking fingerprints of a volunteer/individual) were performed in accordance with relevant guidelines and regulations. An explicit informed consent was obtained from the anonymous volunteer providing the fingerprints. The individual explicitly allowed the authors to use the data in the present publication. And also authors confirmed that all human experimental protocols were approved by a Tumkur University institutional committee.

Note: The authors declare no competing financial interest.

\section{References}

1. Tanveer Ahmad, Dongdong Zhang, A critical review of comparative global historical energy consumption and future demand: The story told so far, Energy Rep., 6 (2020) 1973-1991.

2. K. Svobodov, J.R. Owen, J. Harris, S. Worden, Complexities and contradictions in the global energy transition: A re-evaluation of country-level factors and dependencies, Appl. Energy., 265 (2020) 114778.

3. Qihui Yue, Wuyue Liu, and Xiaozhang Zhu, nType Molecular Photovoltaic Materials: Design Strategies and Device Applications, J. Am. Chem. Soc., 142 (2020) 11613-11628.

4. Lin Dong, Congran Jin, Andrew B. Closson, lan Trase, Haley R. Richards, Zi Chen, John X.J. Zhang, Cardiac energy harvesting and sensing based on piezoelectric and triboelectric designs, Nano Energy., 76 (2020) 105076.

5. Yuan Pu, Lifeng Lin, Jun Liu, Jiexin Wang, Dan Wang, High-gravity-assisted green synthesis of rare-earth doped calcium molybdate colloidal nanophosphors, Chin. J. Chem. Eng., 28 (2020) 1744-1751.

6. Priya Phogat, S.P. khatkar, V.B. Taxak, R.K. Malik, $\mathrm{Sm}^{3+}$ doped $\mathrm{Bi}_{4} \mathrm{MgO}_{4}\left(\mathrm{PO}_{4}\right)_{2}$ : crystal and optoelectronic investigation of the solution combustion derived bright orange emanating novel nanophosphor for SSLS, Mater. Chem. Phys., 276 (2022) 125389.

7. Arpita Dwivedi, Monika Srivastava, S.K. Srivastava, $\mathrm{Ho}^{3+}$ activated $\mathrm{Ca}_{0.5} \mathrm{Y}_{1.90-\mathrm{x}} \mathrm{O}_{3}$ green-emitting nanophosphors for solid state lightening: Synthesis, characterization and photoluminescence properties, J. Mol. Struct., 1251 (2022) 132061.

8. Priya Phogat, S.P. Khatkar, R.K. Malik, Sushma, Jyoti Dalal, Pooja Hooda, V.B. Taxak, Crystal chemistry and photoluminescent investigation of novel white light emanating $\mathrm{Dy}^{3+}$ doped $\mathrm{Ca}{ }_{9} \mathrm{Bi}\left(\mathrm{VO}_{4}\right)_{7}$ nanophosphor for 
ultraviolet based white LEDs, Mater. Chem. Phys., 270 (2021) 124828.

9. Yu Ding, Ning Guo, Miaomiao Zhu, Wenzhen Lv, Ruizhuo Ouyang, Yuqing Miao, Baiqi Shao, Luminescence and temperature sensing abilities of zincate phosphors co-doped bismuth $\mathrm{Bi}^{3+}$ and lanthanide $\mathrm{Eu}^{3+} / \mathrm{Sm}^{3+}$, Mater. Res. Bull., 129 (2020) 110869.

10. Kasturi Singh, Marikumar Rajendran, Rachna Devi, Sivakumar Vaidyanathan, Narrow-band red-emitting phosphor with negligible concentration quenching for hybrid white LEDs and plant growth applications, Dalton Trans., 50 (2021) 4986-5000.

11. M. Dhanalakshmi, R.B. Basavaraj, G.P. Darshan, S.C. Sharma, H. Nagabhushana, Pivotal role of fluxes in $\mathrm{BaTiO}_{3}: \mathrm{Eu}^{3+}$ nano probes for visualization of latent fingerprints on multifaceted substrates and anticounterfeiting applications, Microchem. J., 145 (2019) 226-234.

12. N. Latha, Y.S. Vidya, S.C. Sharma, G.P. Darshan, K.S. Anantharaju, P. Hema Prabha, H. Nagabhushana, Effect of $\mathrm{Li}^{+}$coodoping on the photoluminescence of novel green emitting BiOCl: $\mathrm{Tb}^{3+}$ nanophosphors for display, visualization of latent fingerprints and anticounterfeiting applications, J. Solid State Chem., 290 (2020) 121418.

13. Lifang Yuan, Yahong Jin, Guangting Xiong, Haoyi Wu, Jiacheng Li, Hai Liu, Li Chen, Yihua Hu, Flux-assisted low-temperature synthesis of $\mathrm{Mn}^{4+}$-doped unusual broadband deep-red phosphors toward warm w-LEDs, J. Alloys Compd., 870 (2021) 159394.

14. A. Sandhyarani, M.K. Kokila, G.P. Darshan, H. Nagabhushana, S.C. Sharma, H.B. Premkumar, B. Daruka Prasad, Fabrication of flux supported $\mathrm{SrTiO}_{3}: \mathrm{Eu}^{3+}$ fluorescent powders: New prospective of dual mode ink-free data security applications, J. Sci. Adv. Mater. Devices., 6 (2021) 92-99.

15. Xisong Mao, Xuewen Xia, Junqi Li, Chaoyi Chen, Junshan Zhang, Deyang Ning, Yuan-Pei Lan, Homogenously Rare-Earth-Ion-Doped Nanoceria Synthesis in $\mathrm{KOH}-\mathrm{NaOH}$ Molten Flux: Characterization and Photocatalytic Property, J. Mater. Engineer. Perform., 30 (2021) 3795-3805.

16. Zhengwei Xu, Lei Fu, Lili Liu, Fu Du, Effects of single and composite fluxes on the morphology and luminescence intensity of $\mathrm{Ce}^{3+}$ doped $\mathrm{Lu}_{3} \mathrm{Al}_{5} \mathrm{O}_{12}$ phosphors, Mater. Chem. Phys., 248 (2020) 122918.

17. Nikoletta Laczai, László Kovács, Laura Kocsor, László Bencs, Influence of LiF additive and cerium doping on photoluminescence properties of polycrystalline YSO and LYSO, Mater. Res. Bull., 133 (2021) 111018.

18. K. Ashwini, C. Pandurangappa, K. Avinash, S. Srinivasan, E. Stefanakos, Synthesis, characterization and photoluminescence studies of samarium doped zinc sulfide nanophosphors, J. Lumin., 221 (2020) 117097.

19. Vaibhav Chauhan, Prashant Dixit, Praveen C. Pandey, $\mathrm{Bi}^{3+}$ assisted luminescence in $\mathrm{SrMoO}_{4}: \mathrm{Sm}^{3+}$ red phosphors, J. Rare Earth., 39 (2021) 1336-1343.

20. R. Kamal, M. Saif, Barium tungstate doped with terbium ion green nanophosphor: Low temperature preparation, characterization and potential applications, Spectrochim. Acta, Part A: Molecular and Biomolecular Spectroscopy., 229 (2020) 117928.

21. Inmaculada Ortiz-Gomez, Gloria B. Ramírez-Rodríguez, Luis F. Capit' an-Vallvey, Alfonso Salinas-Castillo, Jos'e M. Delgado-Lopez, Highly stable luminescent europium-doped calcium phosphate nanoparticles for creatinine quantification, Colloids Surf., B: Biointerfaces., 196 (2020) 111337.

22. Subramaniyan Vinoth, M. Govindasamy, Sea-Fue Wang, Asma A. Alothman, Razan A. Alshgari, Surface engineering of roselike lanthanum molybdate electrocatalyst modified screen-printed carbon electrode for robust and highly sensitive sensing of antibiotic drug, Microchem. J., 164 (2021) 106044. 
23. Shifa Wang, Huajing Gao, Guangzhuang Sun, Yanwu Li, Yong Wang, Hufeng Liu, Chaoli Chen, Liang Yang, Structure characterization, optical and photoluminescence properties of scheelite-type $\mathrm{CaWO}_{4}$ nanophosphors: Effects of calcination temperature and carbon skeleton, Opt. Mater., 99 (2020) 109562.

24. Suman Sheoran, Kuldeep Singh, Vijeta Tanwar, Sitender Singh, Anura Samantilleke, Devender Singh, Synthesis and spectroscopic investigations of trivalent europium doped $\mathrm{Z}_{2} \mathrm{Si}_{3} \mathrm{O}_{8}(\mathrm{Z}=\mathrm{Mg}, \mathrm{Ca}$ and $\mathrm{Sr}$ ) nanophosphors for display applications, Rare Met., 40 (2021) 2610-2617.

25. Yiming Li, Xuanyu Meng, Qian Chen, Jiatong Zhu, Jie Xu, Michael J. Reece, Feng Gao, Electronic structure and thermal properties of $\mathrm{Sm}^{3+}$-doped $\mathrm{La}_{2} \mathrm{Zr}_{2} \mathrm{O}_{7}$ : First-principles calculations and experimental study, J Am Ceram Soc., 104 (2021) 1475-1488.

26. Hao Yi, Junwei Che, Zihui Xu, Gongying Liang, Xiangyang Liu, Sintering resistance of $\mathrm{La}_{2} \mathrm{Ce}_{2} \mathrm{O}_{7}, \mathrm{La}_{2} \mathrm{Zr}_{2} \mathrm{O}_{7}$, and yttria stabilized zirconia ceramics, Ceram. Int., 47 (2021) 4197-4205.

27. Xin Min, Yukun Sun, Lingti Kong, Ming Guan, Minghao Fang, Yan'gai Liu, Xiaowen Wu, Zhaohui Huang, Novel pyrochlore-type $\mathrm{La}_{2} \mathrm{Zr}_{2} \mathrm{O}_{7}$ : $\mathrm{Eu}^{3+}$ red phosphors: Synthesis, structural, luminescence properties and theoretical calculation, Dyes Pigm., 157 (2018) 47-54.

28. Santosh K. Gupta, Maya Abdou, Partha S. Ghosh, Jose P. Zuniga, Ezhilarasan Manoharan, HyeongJun Kim, Yuanbing Mao, On comparison of luminescence properties of $\mathrm{La}_{2} \mathrm{Zr}_{2} \mathrm{O}_{7}$ and $\mathrm{La}_{2} \mathrm{Hf}_{2} \mathrm{O}_{7}$ nanoparticles, J. Am. Ceram. Soc., 103 (2020) 235-248.

29. Santosh K. Gupta, Maya Abdou, Jose P. Zuniga, Partha S. Ghosh, Yuanbing Mao, $\mathrm{Li}^{+}$co-doping induced phase transition as an efficient strategy to enhance upconversion of $\mathrm{La}_{2} \mathrm{Zr}_{2} \mathrm{O}_{7}: \mathrm{Er}, \mathrm{Yb}$ nanoparticles, J. Lumin., 224 (2020) 117312.

30. Hamdi Trabelsi, Marx Akl, Samer Hassan Akl, Ultrasound assisted Eu ${ }^{3+}$-doped strontium titanate nanophosphors: Labeling agent useful for visualization of latent fingerprints, Powder Technol., 384 (2021) 70-81.

31. Chuanjun Yuan, Ming Li, Meng Wang, Haijun Cao, Tianchun Lin, A critical review of fundamentals and applications of electrochemical development and imaging of latent fingerprints, Electrochim. Acta., 390 (2021) 138798.

32. Ramanan Vadivel, Muthukumaran Nirmala, Karthikeyani Anbukumaran, Commonly available, everyday materials as non-conventional powders for the visualization of latent fingerprints, Forensic Chem., 24 (2021) 100339.

33. Vishal Sharma, Sonal Choudhary, Priyanka Mankotia, Amrita Kumari, Kashma Sharma, Rakesh Sehgal, Vijay Kumar, Nanoparticles as fingermark sensors, Trends Anal. Chem., 143 (2021) 116378.

34. Hak-Sung Jung, Junsang Cho, Keir C. Neuman, Highly stable cesium lead bromide perovskite nanocrystals for ultrasensitive and selective latent fingerprint detection, Anal. Chim. Acta., 1181 (2021) 338850.

35. D. Navami, G.P. Darshan, D.R. Lavanya, H.B. Premkumar, S.C. Sharma, H. Adarsha, H.C. Prameela, H. Nagabhushana, Design of green emitting $\mathrm{CaZrO}_{3}: \mathrm{Tb}^{3+}$ nanophosphor: Luminescence based platform for realtime ultrasensitive detection of latent fingerprints and anti-counterfeiting applications, Opt. Mater., (2021). doi.org/10.1016/j.optmat.2021.111474.

36. C. Suresh, G.P. Darshan, H.B. Premkumar, S.C. Sharma, H. Adarsha, H.C. Prameela, H. Nagabhushana, Surface Chemistry Modified Core-Shell Structured $\mathrm{SiO}_{2} @ \mathrm{LaOF}: \mathrm{Eu}^{3+} / \mathrm{Li}^{+}$Nanophosphors for Advanced Forensic Applications, J. Sci: Adv. Mater. Devices., (2021). doi.org/10.1016/j.jsamd.2021.09.004.

Page 17/34 
37. Panpan Pan, Tong Zhang, Bingjie Yu, Rongliang Ma, Qin Yue, Abdulaziz A. Alghamdi, Yonghui Deng, A facile construction of bifunctional core-shell magnetic fluorescent $\mathrm{Fe}_{3} \mathrm{O}_{4} @ \mathrm{YVO}_{4}$ : $\mathrm{Eu}^{3+}$ microspheres for latent fingerprint detection, J. Colloid. Interface. Sci., 605 (2022) 425-431.

38. Sara Moreno, Glenna Brown, Mieke Klein, Qiang Wang, John T. Markiewicz, Elvin A. Aleman, Catherine G. Rushton, Rosalynn Quinones, Chemical composition effect on latent print development using black fingerprint powders, Forensic. Chem., 26 (2021) 100366.

39. G Swati, Dipti Bidwai, D Haranath, Red emitting $\mathrm{CaTiO}_{3}: \mathrm{Pr}^{3+}$ nanophosphors for rapid identification of high contrast latent fingerprints, Nanotechnology., 31 (2020) 364007.

40. Di Peng, Xin Wu, Xiang Liu, Mengjun Huang, Dan Wang, Renlong Liu, Color-Tunable Binuclear (Eu, Tb) Nanocomposite Powder for the Enhanced Development of Latent Fingerprints Based on Electrostatic Interactions, ACS Appl. Mater. Interfaces., 10 (2018) 32859-32866.

41. Jun Xu, Beibei Zhang, Lei Jia, Yanping Fan, Rujie Chen, Tinghui Zhu, BaoZhong Liu, Dual-Mode, Color-Tunable, Lanthanide-Doped Core-Shell Nanoarchitectures for Anti-Counterfeiting Inks and Latent Fingerprint Recognition, ACS Appl. Mater. Interfaces., 11 (2019) 35294-35304.

42. Aktanberdi Askerbay, Anara Molkenova, Timur Sh. Atabaev, Latent fingerprint detection with luminescent $\mathrm{Y}_{2} \mathrm{O}_{3}: \mathrm{Eu}^{3+}$ nanoparticles, Mater Today.: Proceed., 20 (2020) 245-248.

43. Jin Young Park, Jong Won Chung, Sung Jun Park, Hyun Kyoung Yang, Versatile fluorescent $\mathrm{CaGdAlO}_{4}: \mathrm{Eu}^{3+}$ red phosphor for latent fingerprints detection, J. Alloys Compd., 824 (2020) 153994.

44. Eluri Pavitraa, Ganji Seeta Rama Rajub, Jin Young Parkc, Sk Khaja Hussaind, Nilesh R. Chodankarb, Gattupalli Manikya Raoe, Young-Kyu Hanb, Yun Suk Huh, An efficient far-red emitting $\mathrm{Ba}_{2} \mathrm{LaNbO}_{6}: \mathrm{Mn}^{4+}$ nanophosphor for forensic latent fingerprint detection and horticulture lighting applications, Ceram. Int., 46 (2020) 98029809.

45. K.N. Venkatachalaiah, H. Nagabhushana, G.P. Darshan, R.B. Basavaraj, B. Daruka Prasad, Novel and highly efficient red luminescent sensor based $\mathrm{SiO}_{2} @ \mathrm{Y}_{2} \mathrm{O}_{3}: \mathrm{Eu}^{3+}, \mathrm{M}^{+}\left(\mathrm{M}^{+}=\mathrm{Li}, \mathrm{Na}, \mathrm{K}\right)$ composite core-shell fluorescent markers for latent fingerprint recognition, security ink and solid state lightning applications, Sens. Actuators, B: Chemical., 251 (2017) 310-325.

46. Yu Wang, Yuee Ke, Shanshan Chen, Junmeng Luo, Shuang Shu, Jing Gao, Bin Deng, Ruijin Yu, Luminescence investigation of red-emitting $\mathrm{Sr}_{2} \mathrm{MgMoO}_{6}: \mathrm{Eu}^{3+}$ phosphor for visualization of latent fingerprint, J. Colloid Interface. Sci., 583 (2021) 89-99.

47. Z. Ghubish, M. Saif, H. Hafez, H. Mahmoud, R. Kamal, M. El-Kemary, Novel red photoluminescence sensor based on Europium ion doped calcium hydroxy stannate $\mathrm{CaSn}(\mathrm{OH})_{6}: \mathrm{Eu}^{+3}$ for latent fingerprint detection, J. Mol. Struct., 1207 (2020) 127840.

48. H.S. Yogananda, G.P. Darshan, S.C. Sharma, H.B. Premkumar, D. Kavyashree, P. Lalitha, H. Nagabhushana, Colour quality parameters and enhanced white light emanation via solution combustion derived $\mathrm{MoO}_{3}: \mathrm{Dy}^{3+}$ micro-architectures: Fluorescent probe for sensitive visualization of latent fingerprints, Opt. Mater., 105 (2020) 109817.

49. Jin Young Park, Hyun Kyoung Yang, Novel red-emitting $\mathrm{Y}_{4} \mathrm{Zr}_{3} \mathrm{O}_{12}$ :Eu ${ }^{3+}$ nanophosphor for latent fingerprinting technology, Dyes Pigm., 141 (2017) 348-355.

50. Wei Wang, Xiang Lei, Zhantong Ye, Nan Zhao, Hua Yang, The luminescent properties and latent fingerprint identification application of AIN:Ce, Tb phosphors, J. Alloys Compd., 705 (2017) 253-261. 
51. N. H. Deepthi, Giriyapura Prabhukumar Darshan, R. B. Basavaraj, B. Daruka Prasad, S. C. Sharma, D. Kavyashree, Hanumanthappa Nagabhushana, Nanostructured Stannic Oxides for White Light Emitting Diodes Provides Authentication for Latent Fingerprints Visualization under Diverse Environmental Conditions, ACS Sustainable Chem. Eng., 7 (2019) 578-591.

52. Hak-Sung Jung, Junsang Cho, Keir C. Neuman, Highly stable cesium lead bromide perovskite nanocrystals for ultrasensitive and selective latent fingerprint detection, Anal. Chim. Acta., 1181 (2021) 338850.

53. C. Suresh, G.P. Darshan, S.C. Sharma, M. Venkataravanappa, H.B. Premkumar, S. Shanthi, K.N. Venkatachalaiah, H. Nagabhushana, Imaging sweat pore structures in latent fingerprints and unclonable anticounterfeiting patterns by sensitizers blended LaOF: Pr ${ }^{3+}$ nanophosphors, Opt. Mater., 100 (2020) 109625.

54. A. Sandhyarani, M.K. Kokila, G.P. Darshan, S.C. Sharma, D. Kavyashree, H.B. Premkumar, H. Nagabhushana, Photometric features and intense blue light emanation of $\mathrm{Nd}^{3+}$ doped $\mathrm{SrTiO}_{3}$ based nanophosphor for multifunctional applications, J. Sci. Adv. Mater. Devices., 5 (2020) 487-496.

55. H.S. Sudheendra, G.P. Darshan, M.K. Kokila, D.R. Lavanya, H.B. Premkumar, S. C. Sharma, H. Adarsha, H. Nagabhushana, Uniform Core-shell $\mathrm{SiO}_{2} @ \mathrm{Sr}_{2} \mathrm{CeO}_{4}: \mathrm{Eu}^{3+}$ nanocomposites: Exploring multiple strategies towards flexible luminescent films and data security applications, Surf. Interfaces., (2021). doi.org/10.1016/j.surfin.2021.101583.

56. Michael Sandborn, Carlos Olea, Jules White, Chris Williams, Pablo A. Tarazaga, Logan Sturm, Mohammad Albakri, Charles Tenney, Towards secure cyber-physical information association for parts, J. Manuf. Syst., 59 (2021) 27-41.

57. Zhi-Jun Zhao, Junseong Ahn, Jiwoo Ko, Yongrok Jeong, Moonjeong Bok, Soon Hyoung Hwang, Hyeok-Joong Kang, Sohee Jeon, Jungrak Choi, Inkyu Park, Jun-Ho Jeong, Shape-Controlled and Well-Arrayed Heterogeneous Nanostructures via Melting Point Modulation at the Nanoscale, ACS Appl. Mater. Interfaces., 13 (2021) 3358-3368.

58. Hao Suo, Qi Zhu, Xin Zhang, Bing Chen, Jiangkun Chen, Feng Wang, High-security anti-counterfeiting through upconversion luminescence, Mater. Today Phys., 21 (2021) 100520.

59. Youhui Zhou, Yao Cheng, Qiugui Huang, Ju Xu, Hang Lin, Yuansheng Wang, Abnormal thermally enhanced upconversion luminescence of lanthanide-doped phosphors: proposed mechanisms and potential applications, J. Mater. Chem. C., 9 (2021) 2220-2230.

60. Chun Sun, Sijing Su, Zhiyuan Gao, Hanxin Liu, Hua Wu, Xinyu Shen, Wengang Bi, Stimuli-Responsive Inks Based on Perovskite Quantum Dots for Advanced Full-Color Information Encryption and Decryption, ACS Appl. Mater. Interfaces., 11 (2019) 8210-8216.

61. Amin Abdollahi, Hossein Roghani-Mamaqani, Bahareh Razavi, and Mehdi Salami-Kalajahi, Photoluminescent and Chromic Nanomaterials for Anticounterfeiting Technologies: Recent Advances and Future Challenges, ACS Nano., 14 (2020) 14417-14492.

62. Santosh K. Gupta, Mitzy A. Penilla Garcia, Jose P. Zuniga, Maya Abdou, Yuanbing Mao, Visible and ultraviolet upconversion and near infrared downconversion luminescence from lanthanide doped $\mathrm{La}_{2} \mathrm{Zr}_{2} \mathrm{O}_{7}$ nanoparticles, J. Lumin., 214 (2019) 116591.

63. Fiza Mumtaz, G. Hassnain Jaffari, Qadeer ul Hassan, S. Ismat Shah, Correlation between ionic size and valence state of tetra, penta and hexavalent B-site substitution with solubility limit, phase transformation and multiferroic properties of $\mathrm{Bi}_{0.875} \mathrm{Eu}_{0.125} \mathrm{FeO}_{3}$, Physica B: Condensed Matter., 538 (2018) 213-224. 
64. Fengwen Kang, Guohuan Sun, Philippe Boutinaud, Haoyi Wu, Fei-Xiang Ma, Jian Lu, Jiulin Gan, Haidong Bian, Fei Gao, Sanshui Xiao, Recent advances and prospects of persistent luminescent materials as inner secondary self-luminous light source for photocatalytic applications, Chem. Eng. J., 403 (2021) 126099.

65. Haohao Wang, Yujie Liu, Xudong Zhu, Liangshu Wei, Xiping Jiang, Yong Chen, Langkai Li, Preparation of CaAISiN3:Eu2+ red-emitting phosphor by a two-step method for solid-state lighting applications, Ceram. Int., 46 (2020) 23035-23040.

66. Yuexiang Li, Yuan Jiang, Shaoqin Peng, Fengyi Jiang, Nitrogen-doped $\mathrm{TiO}_{2}$ modified with NH4F for efficient photocatalytic degradation of formaldehyde under blue light-emitting diodes, J. Hazard. Mater., 182 (2010) 90-96.

67. Petra Simonov, Willi Pabst, Jana Cibulkov, Crystallite size of pure tin oxide ceramics and its growth during sintering determined from XRD line broadening - A methodological case study and a practitioner's guide, Ceram. Int., (2021).

68. Madhab Pokhrel, Arnold Burger, Michael Groza, Yuanbing Mao, Enhance the photoluminescence and radioluminescence of $\mathrm{La}_{2} \mathrm{Zr}_{2} \mathrm{O}_{7}: \mathrm{Eu}^{3}+$ core nanoparticles by coating with a thin $\mathrm{Y}_{2} \mathrm{O}_{3}$ shell, Opt. Mater., 68 (2017) 35-41.

69. Devendra Pakhare, Viviane Schwartz, Victor Abdelsayed, Daniel Haynes, Dushyant Shekhawat, James Poston, James Spivey, Kinetic and mechanistic study of dry $\left(\mathrm{CO}_{2}\right)$ reforming of methane over Rh-substituted $\mathrm{La}_{2} \mathrm{Zr}_{2} \mathrm{O}_{7}$ pyrochlores, J. Catal., 316 (2014) 78-92.

70. Anju Siwach, Dinesh Kumar, Structural and optical behavior of nano-scaled luminous green-emitting $\mathrm{Ca}_{9} \mathrm{Y}\left(\mathrm{PO}_{4}\right)_{7}: \mathrm{Tb}^{3+}$ phosphor for competent lighting devices, Chem. Phys. Lett., 772 (2021) 138547.

71. H. Jamil, I.M. Dildar, Usman Ilyas, J.Z. Hashmi, Saima Shaukat, M.N. Sarwar, M. Khaleeq-ur-Rahman, Microstructural and Optical study of polycrystalline manganese oxide films using Kubelka-Munk function, Thin Solid Films., 732 (2021) 138796.

72. Yongfu Liu, Jianxin Zhang, Changhua Zhang, Jun Jiang, Haochuan Jiang, High Efficiency Green Phosphor $\mathrm{Ba}_{9} \mathrm{Lu}_{2} \mathrm{Si}_{6} \mathrm{O}_{24}: \mathrm{Tb}^{3+}$ : Visible Quantum Cutting via Cross-Relaxation Energy Transfers, J. Phys. Chem. C., 120 (2016) 2362-2370.

73. Sushma Devi, Avni Khatkar, Anju Hooda, V.B. Taxak, Priti Boora, Priyanka Dhankhar, S.P. Khatkar, Structural and optical investigation of $\mathrm{Tb}^{3+}$-doped $\mathrm{Ba}_{3} \mathrm{Y}_{4} \mathrm{O}_{9}$ nanocrystals for solid state lighting applications, J. Solid State. Chem., 288 (2020) 121333.

74. T.O. Sales, R.J. Amjad, C. Jacinto, M.R. Dousti, Concentration dependent luminescence and cross-relaxation energy transfers in $\mathrm{Tb}^{3+}$ doped fluoroborate glasses, J. Lumin., 205 (2019) 282-286.

75. D.N. Gamea, N.B. Ingale, S.K. Omanwar, Converted white light emitting diodes from $\mathrm{Ce}^{3+}$ doping of alkali earth sulfide phosphors, Mater. Discover., 4 (2016) 1-7.

76. Ravina, Naveen, Sheetal, V. Kumar, S. Dahiya, Nisha Deopa, R. Punia, A.S. Rao, Judd-Ofelt itemization and influence of energy transfer on $\mathrm{Sm}^{3+}$ ions activated $\mathrm{B}_{2} \mathrm{O}_{3}-\mathrm{ZnF}_{2}-\mathrm{SrO}-\mathrm{SiO}_{2}$ glasses for orange-red emitting devices, J. Lumin., 229 (2021) 117651.

77. Sushma Devi, Avni Khatkar, V.B. Taxak, Anju Hooda, Priyanka Sehrawat, Sonika Singh, S.P. Khatkar, Influence of $\mathrm{Tb}^{3+}$ doping on the structural and down-conversion luminescence behaviour of $\mathrm{SrLaAlO}_{4}$ nanophosphor, $\mathrm{J}$. Lumin., 221 (2020) 117064. 
78. C. Shivakumara, Rohit Saraf, Pramod Halappa, White luminescence in $\mathrm{Dy}^{3+}$ doped BiOCl phosphors and their Judd-Ofelt analysis, Dyes Pigm., 126 (2016) 154-164.

79. Fengmin Song, Synthesis and photoluminescence of new Eu ${ }^{3+}$-activated $\mathrm{Cs}_{2} \mathrm{Ba}\left(\mathrm{MoO}_{4}\right)_{2}$ red-emitting phosphors with high color purity for white LEDs, Journal of Luminescence., 239 (2021) 118324.

80. Mohamed Zikriya, Y. F. Nadaf, C. Manjunath, C. G. Renuka, Microstructural and optical properties of rare earth ions doped $\mathrm{TiO}_{2}$ for potential white LED applications, J. Mater. Sci. Mater. Electron., 29 (2018) 16824-16835.

81. Ram Sagar Yadav, Shyam Bahadur Rai, Concentration and wavelength dependent frequency downshifting photoluminescence from a $\mathrm{Tb}^{3+}$ doped yttria nano-phosphor: A photochromic phosphor, J. Phys. Chem. Solids., 114 (2018) 179-186.

82. Sitender Singh, Devender Singh, Down-conversion and structural characterizations of trivalent terbium-doped garnet nanocrystalline phosphors for lighting applications, J. Mater. Sci. Mater. Electron., 32 (2021) 1767417685.

83. P.K. Jisha, S.C. Prashantha, H. Nagabhushana, Luminescent properties of Tb doped gadolinium aluminate nanophosphors for display and forensic applications, J. Sci. Adv. Mater. Devices., 2 (2017) 437-444.

84. Kai Li, Sisi Liang, Hongzhou Lian, Mengmeng Shang, Bengang Xing, Jun Lin, Ce ${ }^{3+}$ and $\mathrm{Tb}^{3+}$-doped lutetiumcontaining silicate phosphors: synthesis, structure refinement and photoluminescence properties, J. Mater. Chem. C., 4 (2016) 3443.

85. Jie Ding, Qiang Zhang, Jimeng Cheng, Xiaofeng Liu, Geng Lin, Jianrong Qiu, Danping Chen, Multicolor upconversion luminescence from $\mathrm{RE}^{3+} \mathrm{Yb}^{3+}(\mathrm{RE}=\mathrm{Er}, \mathrm{Tm}, \mathrm{Tb})$ codoped $\mathrm{LaAlGe}_{2} \mathrm{O}_{7}$ glasses, J. Alloys Compd., 495 (2010) 205-208.

86. Zhifeng Xing, Mengmeng Lun, Wanying Wu, Hanzhao Song, Aihua Yao, Xunsheng Zhou, Yinzhen Wang, Benli Chu, Wei Li, Qinyu He, Guannan He, Photoluminescence and unique magnetoluminescence of transparent $\left(\mathrm{Tb}_{1-\mathrm{x}} \mathrm{Y}_{\mathrm{x}}\right)_{3} \mathrm{Al}_{5} \mathrm{O}_{12}$ ceramics, Ceram. Int., 46 (2020) 8971-8978.

87. Xinguo Zhang, Jiabao Luo, Zishan Sun, Weiying Zhou, Zhan-Chao Wu, Jilin Zhang, Ultrahigh-Energy-Transfer

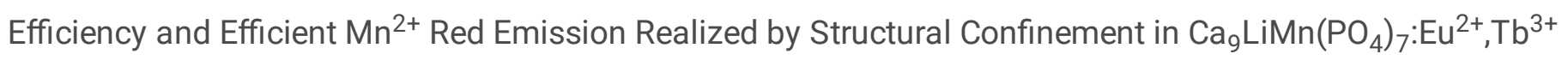
Phosphor, Inorg. Chem., 59 (2020) 15050-15060.

88. N. F. Andrade Neto, J. M. P. Silva, R. L. Tranquilin, E. Longo, J. F. M. Domenegueti, M. R. D. Bomio, F. V. Motta, Photoluminescent properties of $\mathrm{Sm}^{3+}$ and $\mathrm{Tb}^{3+}$ codoped $\mathrm{CaWO}_{4}$ nanoparticles obtained by a one-step sonochemical method, J. Mater. Sci. Mater. Electron., 31 (2020) 13261-13272.

89. R.B. Basavaraj, H. Nagabhushana, G.P. Darshan, B. Daruka Prasad, M. Rahul, S.C. Sharma, R. Sudaramani, K.V. Archana, Red and green emitting $\mathrm{CTAB}$ assisted $\mathrm{CdSiO}_{3}: \mathrm{Tb}^{3+} / \mathrm{Eu}^{3+}$ nanopowders as fluorescent labeling agents useful for forensic and display applications, Dyes Pigm., 147 (2017) 364-377.

90. V.S. Kavitha, R. Reshmi Krishnan, R. Sreeja Sreedharan, K. Suresh, C.K. Jayasankar, V.P. Mahadevan Pillai, $\mathrm{Tb}^{3+}$-doped $\mathrm{WO}_{3}$ thin films: A potential candidate in white light emitting devices, J. Alloys Compd., 788 (2019) $429-445$.

91. Santosh K. Gupta, Jose P. Zuniga, Maya Abdou, Melonie P. Thomas, Manisha De Alwis Goonatilleke, Beth S. Guiton, Yuanbing Mao, Lanthanide-doped lanthanum hafnate nanoparticles as multicolor phosphors for warm white lighting and scintillators, Chem. Engineer. J., 379 (2020) 122314.

92. S. Ashwini, S.C. Prashantha, Ramachandra Naik, Yashwanth V. Naik, H. Nagabhushana, D.M. Jnaneshwara, Photoluminescence of a novel green emitting $\mathrm{Bi}_{2} \mathrm{O}_{3}: \mathrm{Tb}^{3+}$ nanophosphors for display, thermal sensor and 
visualisation of latent fingerprints, Optik - Int. J. Light Electron Optics., 192 (2019) 162956.

93. Sumara Khursheed, Vinay Kumar, Vivek K. Singh, H. C. Swart, Jitendra Sharma, Study of luminescence from terbium doped strontium borate nanophosphors in PMMA, Applied Phys. A., 127 (2021).

94. Manju Dahiya, Anju Siwach, Mandeep Dalal, Dinesh Kumar, Study of structural and luminescent characteristics of novel color tunable blue-green $\mathrm{Tb}^{3+}$-doped $\mathrm{Na}_{3} \mathrm{Y}\left(\mathrm{PO}_{4}\right)_{2}$ nanoparticles for NUV-based WLEDs, J. Mater. Sci. Mater. Electron., 32 (2021) 4166-4176.

95. Sitender Singh, Devender Singh, Down-conversion and structural characterizations of trivalent terbium-doped garnet nanocrystalline phosphors for lighting applications, J. Mater. Sci. Mater. Electron., 32 (2021) 1767417685.

96. Peng Du, Yongbin Hua, Jae Su Yu, Room-temperature synthesis of near-ultraviolet light-excited $\mathrm{Tb}^{3+}$-doped $\mathrm{NaBiF}_{4}$ green-emitting nanoparticles for solid-state lighting, RSC Adv., 8 (2018) 26676-26681.

97. Shubham Srivastava, Shantanu K. Behera, Bibhuti B. Nayak, Optimization and photoluminescence behaviour of terbium doped $\mathrm{YBO}_{3}$ phosphors, Opt. Mater., 107 (2020) 110178.

98. T. Samuel, Ch. Satya Kamal, Srikanth Ravipati, Babajide Patrick Ajayi, V. Veeraiah, V. Sudarsan, K. Ramachandra Rao, High purity green photoluminescence emission from $\mathrm{Tb}^{3+}, \mathrm{Bi}^{3+}$ co-doped $\mathrm{LaGaO}_{3}$ nanophosphors, Opt. Mater., 69 (2017) 230-237.

99. R.de Jong, M.de Puit, Fluorescent metal organic frameworks for the visual enhancement of latent fingermarks, Forensic Sci. Int., 291 (2018) 12-16.

100. Sébastien Moret, Esther Scott, Adrian Barone, Kang Liang, Chris Lennard, Claude Roux, Xanthe Spindler, MetalOrganic Frameworks for fingermark detection - A feasibility study, Forensic Sci. Int., 291 (2018) 83-93.

101. M. K. Ravindra, G. P. Darshan, D. R. Lavanya, K. M. Mahadevan, H. B. Premkumar, S. C. Sharma, H.Adarsha, H. Nagabhushana, Aggregation induced emission based active conjugated imidazole luminogens for visualization of latent fngerprints and multiple anticounterfeiting applications, 11 (2021).

102. Muniswamy Dhanalakshmi, Hanumanthappa Nagabhushana, R. B. Basavaraj, Giriyapura Prabhukumar Darshan, B. Daruka Prasad, Surfactant-Assisted $\mathrm{BaTiO}_{3}: \mathrm{Eu}^{3+} @ \mathrm{SiO}_{2}$ Core-Shell Superstructures Obtained by Ultrasonication Method: Dormant Fingerprint Visualization and Red Component of White Light-Emitting Diode Applications, ACS Sustainable Chem. Eng., 6 (2018) 5214-5226.

103. M. Dhanalakshmi, H. Nagabhushana, G.P. Darshan, B. Daruka Prasad, Ultrasound assisted sonochemically engineered effective red luminescentlabeling agent for high resolution visualization of latent fingerprints, Mater. Res. Bull., 98 (2018) 250-264.

104. Vinita Bhardwaj, Thangaraj Anand, Seshu Varddhan, SK Ashok Kumar, Guido Crisponi, Suban K Sahoo, Aggregation-induced emission active vitamin $\mathrm{B}_{6}$ cofactor derivative: applications in $\mathrm{pH}$ sensing and detection of latent fingerprints, Photochem. Photobiol. Sci., 19 (2020) 1402-1409.

105. A. Sandhyarani, M.K. Kokila, G.P. Darshan, R.B. Basavaraj, B. Daruka Prasad, S.C. Sharma, T.K.S. Lakshmi, H. Nagabhushana, Versatile core-shell $\mathrm{SiO}_{2} @ \mathrm{SrTiO}_{3}: \mathrm{Eu}^{3+}, \mathrm{Li}^{+}$nanopowders as fluorescent label for the visualization of latent fingerprints and anti-counterfeiting applications, Chem. Engineer. J., 327 (2017) 11351150.

106. C. Suresh, Y.S. Vidya, H. Nagabhushana, K.S. Anantharaju, M. Venkataravanappa, K. Umeshareddy, Centella asiaticamediated solution combustion synthesis of a novel $\mathrm{Pr}^{3+}$ doped Lanthanum Oxyfluoride for display 
and visualization of latent fingerprints and anticounterfeiting applications, J. Sci. Adv. Mater. Devices., 6 (2021) 75-83.

107. Pawan Kumar, Jaya Dwivedi, Bipin Kumar Gupta, Highly-luminescent dual mode rare-earth nanorods assisted multi-stage excitable security ink for anti-counterfeiting applications, J. Mater. Chem. C., 2 (2014) 1046810475 .

108. Quan Zhang, Jin Tang, Peng Du, Weiping Li, Guoliang Yuan, Zhifu Liu, Laihui Luo, Reversible and color controllable emissions in $\mathrm{Er}^{3+} / \mathrm{Pr}^{3+}$-codoped $\mathrm{K}_{0.5} \mathrm{Na}_{0.5} \mathrm{NbO}_{3}$ ceramics with splendid photochromic properties for anti-counterfeiting applications, J. Eur. Ceram. Soc., 41 (2021) 1904-1916.

109. Yujian Wu, Xiaoqi Zhao, Zhiyu Zhang, Jinmeng Xiang, Hao Suo, Chongfeng Guo, Dual-mode dichromatic $\mathrm{SrBi}_{4} \mathrm{Ti}_{4} \mathrm{O}_{15}: \mathrm{Er}^{3+}$ emitting phosphor for anti-counterfeiting application, Ceram. Int., 47 (2021) 15067-15072.

110. Sicong Zhao, Min Gao, Jingfang Li, Lanthanides-based luminescent hydrogels applied as luminescent inks for anti-counterfeiting, J. Lumin., 236 (2021) 118128.

111. Qing-Feng Li, Shaowen Chu, Erqing Li, Meng Li, Jin-Tao Wang, Zhenling Wang, Lanthanide-based hydrogels with adjustable luminescent properties synthesized by thiol-Michael addition, Dyes Pigm., 174 (2020) 108091.

112. Xi Chen, Yuru Wang, Ran Chai, Yang Xu, Huanrong Li, Binyuan Liu, Luminescent Lanthanide-Based Organic/Inorganic Hybrid Materials for Discrimination of Glutathione in Solution and within Hydrogels, ACS Appl. Mater. Interfaces., 9 (2017) 13554-13563.

113. Oxana Kotova, Samuel J. Bradberry, Aramballi J. Savyasachi, Thorfinnur Gunnlaugsson, Recent advances in the development of luminescent lanthanide-based supramolecular polymers and soft materials, Dalton Trans., 47 (2018) 16377.

114. Qi Zhou, Xuelin Dong, Yuxiang Xiong, Binbin Zhang, Shan Lu, Qin Wang, Yonggui Liao, Yajiang Yang, Hong Wang, Multi-Responsive Lanthanide-Based Hydrogel with Encryption, Naked Eye Sensing, Shape Memory, SelfHealing, and Antibacterial Activity, ACS Appl. Mater. Interfaces., 12 (2020) 28539-28549.

115. Qing-Feng Li, Shaohua Sun, Shaowen Chu, Lin Jin, Jin-Tao Wang, Zhenling Wang, Luminescent hydrogels with tunable emission colors and excellent adhesion performance fabricated by lanthanide complexes induced crosslinking and physical interaction, Polymer, 236 (2021) 124319.

\section{Tables}

Table 1

Previous literature of various materials used for visualization of LFPs followed by powder dusting method. 


\begin{tabular}{|c|c|c|c|c|c|c|}
\hline $\begin{array}{l}\text { SI. } \\
\text { No }\end{array}$ & Sample & $\begin{array}{l}\text { Source of } \\
\text { excitation } \\
(\mathrm{nm})\end{array}$ & Surfaces & $\begin{array}{l}\text { Extracted } \\
\text { ridge } \\
\text { details }\end{array}$ & $\begin{array}{l}\text { Aging } \\
\text { (days) }\end{array}$ & References \\
\hline 1 & $\mathrm{CaTiO}_{3}: \mathrm{Pr}^{3+}$ & 345 & $\begin{array}{l}\text { Holograms, } \\
\text { compact disk }\end{array}$ & Type I-III & - & Swati et al. [39] \\
\hline 2 & $\begin{array}{l}\mathrm{Eu}_{\mathrm{x}} \mathrm{Tb}_{1-\mathrm{x}}(\mathrm{AA})_{3} \\
\text { Phen complexes }\end{array}$ & 312 & $\begin{array}{l}\text { Plastic sheets, } \\
\text { aluminum alloy, } \\
\text { ceramic tiles, } \\
\text { painted wood, } \\
\text { leather and } \\
\text { transparent } \\
\text { glass }\end{array}$ & Type I-III & 90 & Peng et al. [40] \\
\hline 3 & $\begin{array}{l}\mathrm{Y}_{2} \mathrm{O}_{3}: \mathrm{Er}^{3+}, \\
\mathrm{Yb}^{3+} @ \mathrm{SiO}_{2} @ L G d E u x \mathrm{~Tb}_{1-\mathrm{x}} \mathrm{H}\end{array}$ & 254 & $\begin{array}{l}\text { Glass petri dish, } \\
\text { glass, mouse, } \\
\text { ceramic tile, }\end{array}$ & Type I-II & - & Jun Xu et al. [41] \\
\hline & $-P M A$ & & knife, wood & & & \\
\hline 4 & $\mathrm{Y}_{2} \mathrm{O}_{3}: \mathrm{Eu}^{3+}$ & - & $\begin{array}{l}\text { Aluminum foil, } \\
\text { glass, plastic }\end{array}$ & Type I-II & - & $\begin{array}{l}\text { Askerbay et al. } \\
\text { [42] }\end{array}$ \\
\hline 5 & $\mathrm{CaGdAlO}_{4}: \mathrm{Eu}^{3+}$ & 254 & $\begin{array}{l}\text { Glass, aluminum } \\
\text { foil, compact } \\
\text { disc, stainless } \\
\text { steel, } \\
\text { plastic tube, } \\
\text { compact disc }\end{array}$ & Type I-III & - & Park et al. [43] \\
\hline 6 & $\mathrm{Ba}_{2} \mathrm{LaNbO}_{6}: \mathrm{Mn}^{4+}$ & 365 & $\begin{array}{l}\text { Stainless steel, } \\
\text { aluminum foil, } \\
\text { glass, plastic }\end{array}$ & Type I-III & 5 & Pavitra et al. [44] \\
\hline 7 & $\begin{array}{l}\mathrm{SiO}_{2} @ \mathrm{Y}_{2} \mathrm{O}_{3}: \mathrm{Eu}^{3+}, \mathrm{M}^{+}\left(\mathrm{M}^{+}=\right. \\
\mathrm{Li}, \mathrm{Na}, \mathrm{K})\end{array}$ & 254 & $\begin{array}{l}\text { Bank currency, } \\
\text { papers, pellet die, } \\
\text { steel, textured } \\
\text { marbles, wooden } \\
\text { floor, coin, } \\
\text { compact disk, } \\
\text { glass, credit } \\
\text { cards }\end{array}$ & Type I-III & - & $\begin{array}{l}\text { Venkatachalaiah } \\
\text { et al. [45] }\end{array}$ \\
\hline 8 & $\mathrm{Sr}_{2} \mathrm{MgMoO}_{6}: \mathrm{Eu}^{3+}$ & 395 & Aluminum foil & Type I-III & - & Wang et al. [46] \\
\hline 9 & $\mathrm{CaSn}(\mathrm{OH})_{6}: \mathrm{Eu}^{3+}$ & 254 & $\begin{array}{l}\text { Glass, ceramic, } \\
\text { highlighter, }\end{array}$ & Type I-III & 90 & $\begin{array}{l}\text { Ghubish et al. } \\
\text { [47] }\end{array}$ \\
\hline
\end{tabular}

Page 24/34 
aluminum foil,

color paper, leaf,

currency

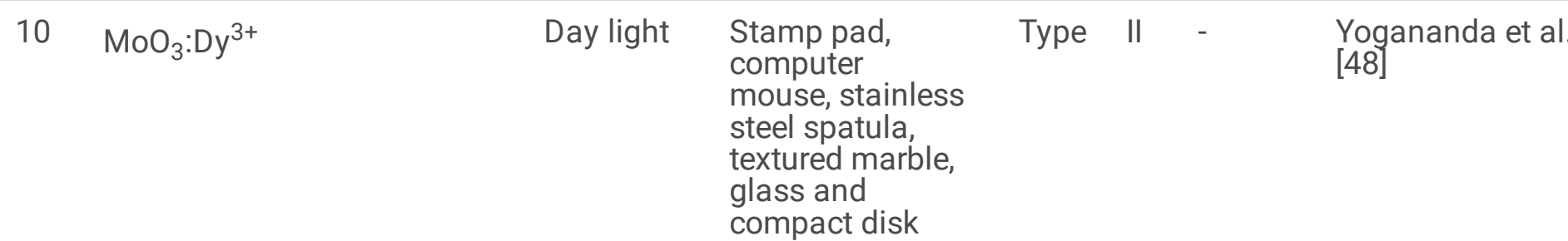

$11 \quad \mathrm{Y}_{4} \mathrm{Zr}_{3} \mathrm{O}_{12}: \mathrm{Eu}^{3+}$

254

Glass, aluminum Type I-III - $\quad$ Park et al. [49]

foil,

compact disc,

steel, plastic,

passport

$12 \quad$ AIN:Ce, Tb

Metal, paper,

plastic, steel,

Type I- -

Wang et al. [50]

cardboard,

transparent

plastic, bank

card

$13 \mathrm{SnO}_{2}: \mathrm{Eu}^{3+}$

254

Highlighter,

Level I-III 5

sprayer, granite,

II

Park et al. [49]

soft drink can,

leaf

Deepthi et al.

[51]

$14 \mathrm{CsPbBr}_{3}$

455

Aluminium foil, Level I-II $14 \quad$ Jung et al. [52]

ceramic, glass,

paper,

transparent

plastic, wood

15

$\begin{aligned} & \mathrm{La}_{2} \mathrm{Zr}_{2} \mathrm{O}_{7}: \mathrm{Tb}^{3+}, \mathrm{NH}_{4} \mathrm{Cl} \quad 254 \quad \text { Glass, } \\ & \text { aluminium foil, } \\ & \text { ceramic, glass, } \\ & \text { paper, } \\ & \text { transparent } \\ & \text { plastic, etc. }\end{aligned}$

Level I-III

24

Present work

Table 2

List of various minute level-III ridge details of the developed FPs of two different donors. 


\begin{tabular}{|c|c|c|c|c|c|}
\hline Ridge details & $\begin{array}{l}\text { Donor } \\
1\end{array}$ & $\begin{array}{l}\text { Donor } \\
2\end{array}$ & Ridge details & Donor 1 & Donor 2 \\
\hline \multirow{10}{*}{ Width of ridges $(\mu \mathrm{m})$} & 227 & 313 & \multirow{10}{*}{ Ridge bifurcation (deg) } & 30 & 37 \\
\hline & 284 & 394 & & 27 & 49 \\
\hline & 317 & 375 & & 13 & 66 \\
\hline & 369 & 431 & & 28 & 59 \\
\hline & 499 & 363 & & 54 & 50 \\
\hline & 328 & 389 & & 39 & 25 \\
\hline & 270 & 288 & & 25 & 17 \\
\hline & 268 & 396 & & 24 & 51 \\
\hline & 190 & 256 & & 40 & 33 \\
\hline & 502 & 421 & & 26 & 45 \\
\hline \multirow{11}{*}{$\begin{array}{l}\text { Separation between pores } \\
(\mu \mathrm{m})\end{array}$} & 241 & 363 & \multirow{11}{*}{$\begin{array}{l}\text { Enabled ridge } \\
\text { characteristics }\end{array}$} & Short ridge & Loop \\
\hline & 298 & 310 & & Eye & Ridge end \\
\hline & 622 & 626 & & Ridge end & Hook \\
\hline & 369 & 583 & & Hook & Crossover \\
\hline & 535 & 568 & & Delta & Delta \\
\hline & 577 & 556 & & Crossover & Enclosure \\
\hline & 682 & 654 & & Specialty & Dot \\
\hline & 464 & 506 & & Dot & Scars \\
\hline & 249 & 466 & & Lake & Sweat pores \\
\hline & 303 & 332 & & & \\
\hline & & & & $\begin{array}{l}\text { Sweat } \\
\text { pores }\end{array}$ & $\begin{array}{l}\text { Incipient } \\
\text { ridge }\end{array}$ \\
\hline
\end{tabular}

\section{Figures}



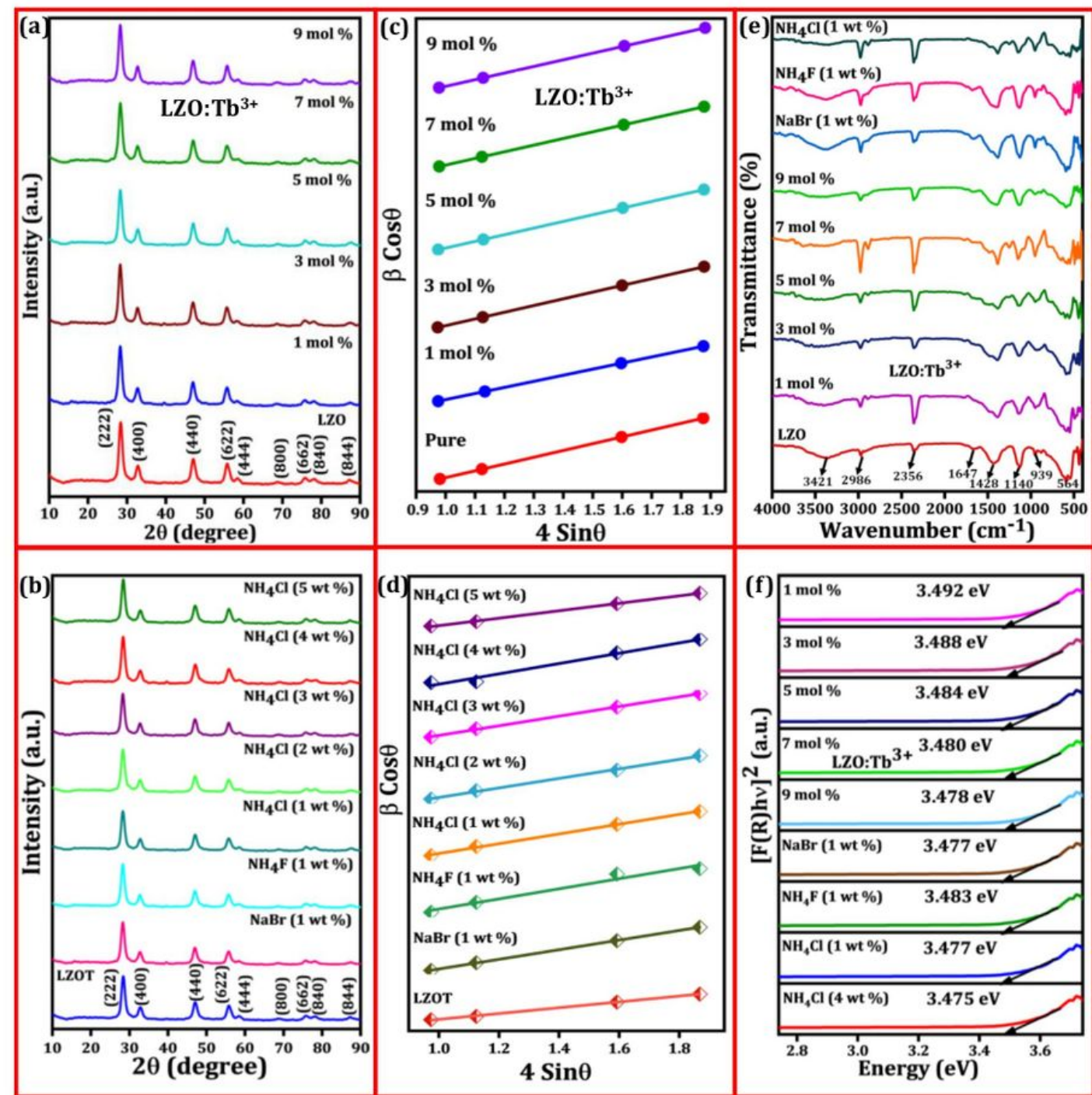

Figure 1 (a) PXRD profiles of prepared LZO sample and $\mathrm{Tb}^{3+}(1-9 \mathrm{~mol} \%)$ doped LZO NPs calcined at $\sim 800{ }^{\circ} \mathrm{C}$ for $\sim 3 \mathrm{~h}$; (b) PXRD profiles of LZOT NPs and various fluxes $(\mathrm{NaBr}$, $\mathrm{NH}_{4} \mathrm{~F}$ and $\mathrm{NH}_{4} \mathrm{Cl}$ ) conjugated LZOT NPs; (c, d) W-H plots of the corresponding samples of (a) and (b); (e) FT-IR spectra of the LZO, LZO:Tb ${ }^{3+}$ (1-9 mol \%) NPs and LZOT: NaBr, $\mathrm{NH}_{4} \mathrm{~F}$, $\mathrm{NH}_{4} \mathrm{Cl}$ (1 wt. \%) NPs; (f) Energy band gap plots of the LZO:Tb ${ }^{3+}(1-9 \mathrm{~mol} \%)$ NPs and fluxes assisted LZOT NPs estimated using K-M function.

\section{Figure 1}

Please See image above for figure legend. 

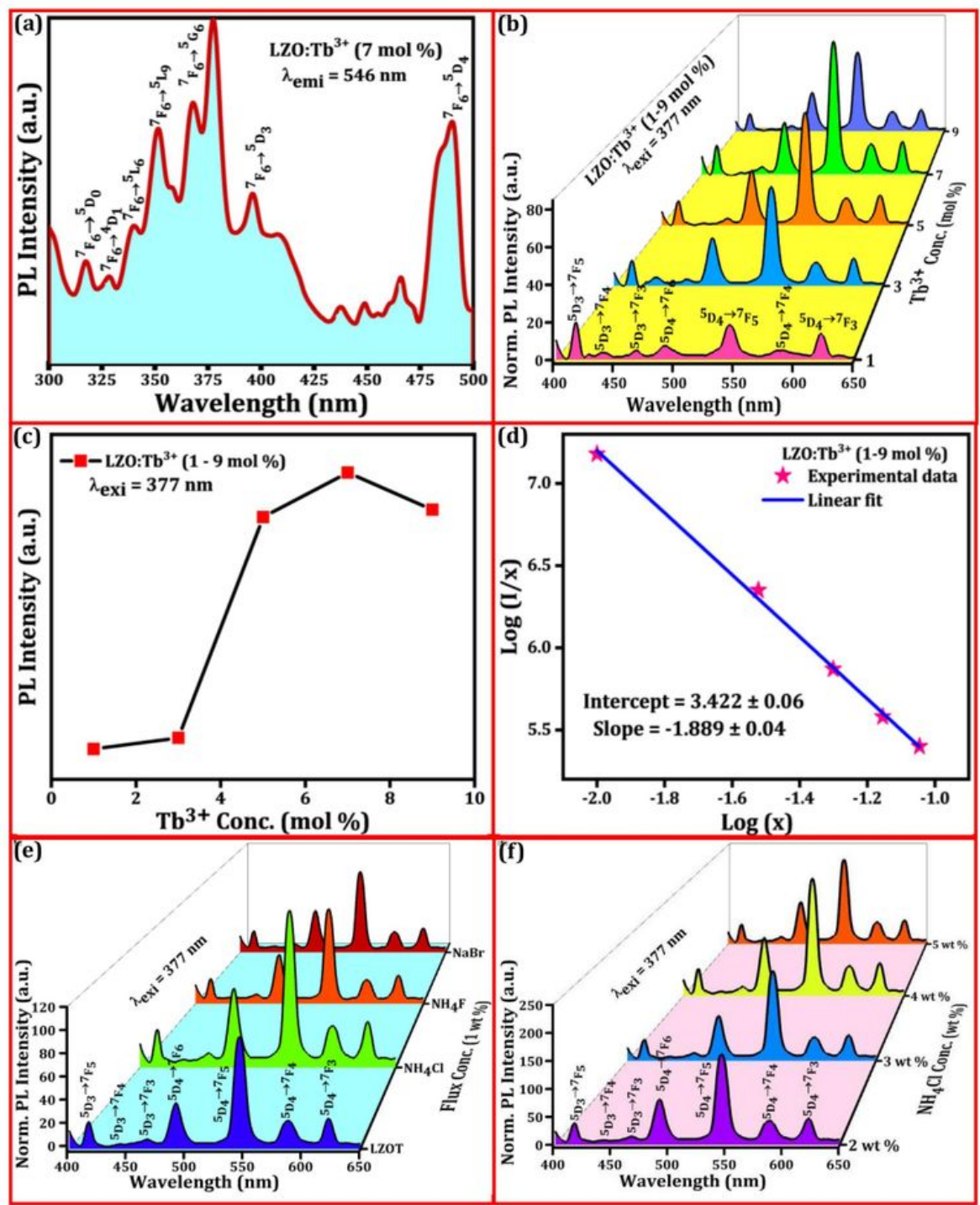

Figure 2 (a) PL excitation spectrum of the LZO: $\mathrm{Tb}^{3+}(7 \mathrm{~mol} \%)$ NPs upon $\sim 546 \mathrm{~nm}$ emission wavelength at room temperature; (b) PL emission spectra of the LZO: $\mathrm{Tb}^{3+}(1-9 \mathrm{~mol} \%) \mathrm{NPS}$ excited at $\sim 377 \mathrm{~nm}$; (c) Variation plot of the PL intensity versus different concentrations of the $\mathrm{Tb}^{3+}$ ions, which showing maximum intensity was obtained for $7 \mathrm{~mol} \%$ of $\mathrm{Tb}^{3+}$ ions; (d) Logarithmic plot of $\mathrm{Tb}^{3+}$ ions concentration (x) versus (I/x); (e) PL emission spectra of the LZOT and LZOT: $\mathrm{NH}_{4} \mathrm{Cl}, \mathrm{NH}_{4} \mathrm{~F}, \mathrm{NaBr}$ (1 wt. \%) NPs excited at $\sim 377 \mathrm{~nm}$; (f) PL emission spectra of the LZOT: $\mathrm{NH}_{4} \mathrm{Cl}(2-5$ wt. \%) NPs, showing highest intensity for 4 wt. \% conjugated NPs.

\section{Figure 2}

Please See image above for figure legend. 

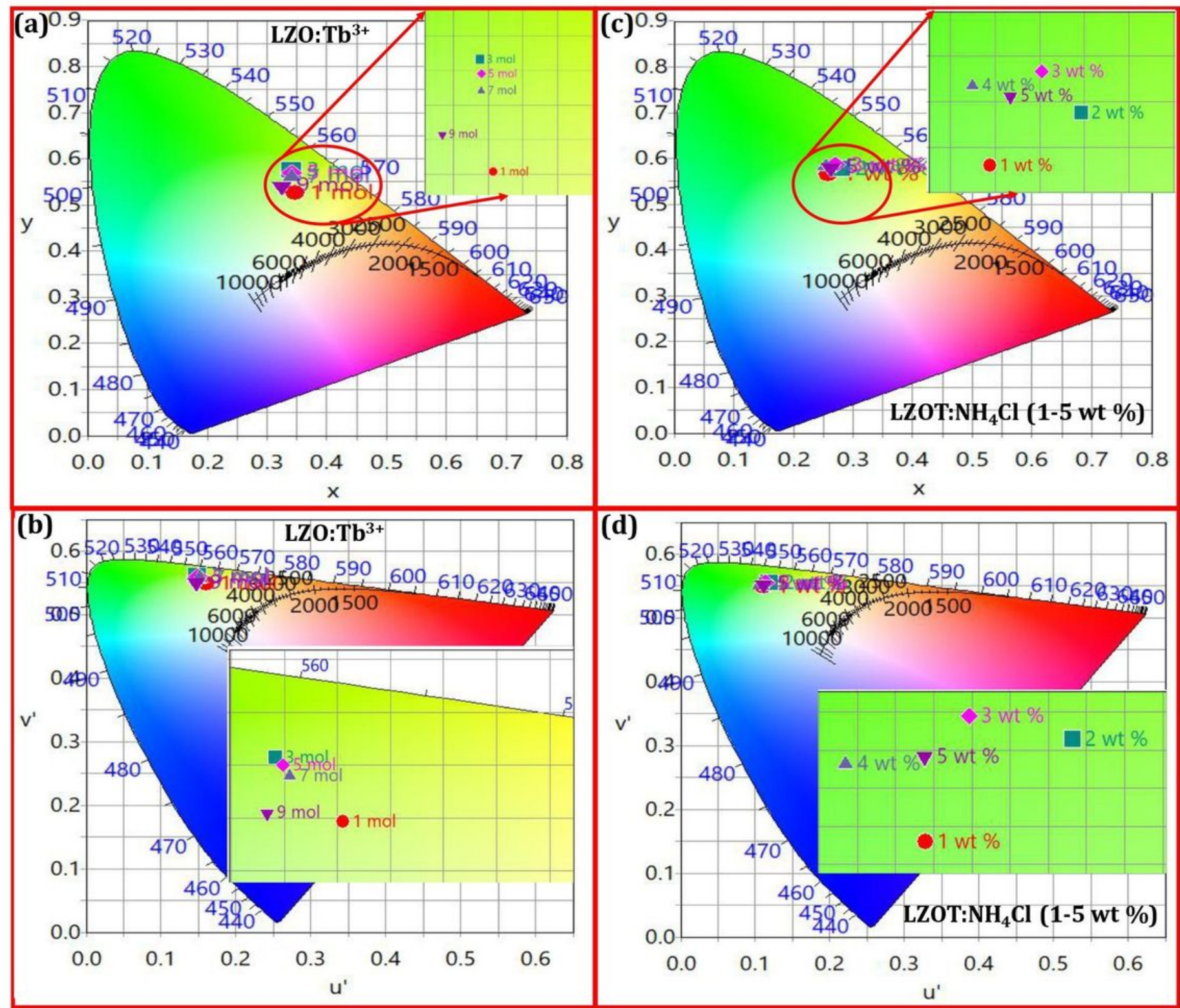

Figure 3 (a \& c) CIE diagrams of the LZO: $\mathrm{Tb}^{3+}$ (1-9 mol \%) NPs and LZOT:NH $4 \mathrm{Cl}(1-5 \mathrm{wt}$. \%) NPs; (b \& d) CCT diagrams of the corresponding samples of (a) and (c).

Figure 3

Please See image above for figure legend. 


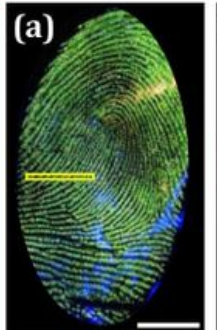

Compact disc

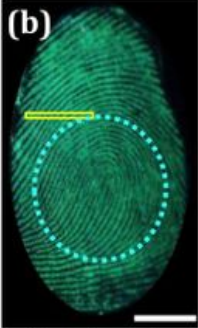

Metal scale

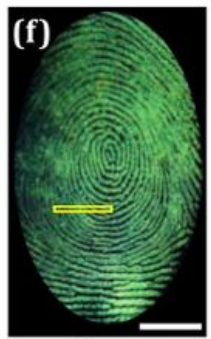

Paper

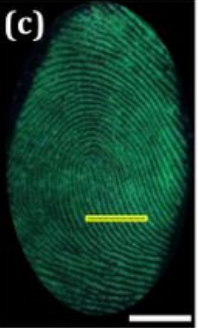

Glass

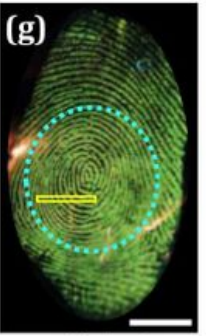

Ticket

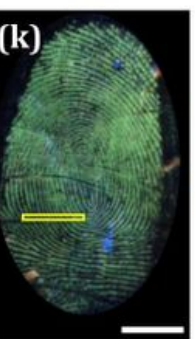

Aluminium foil
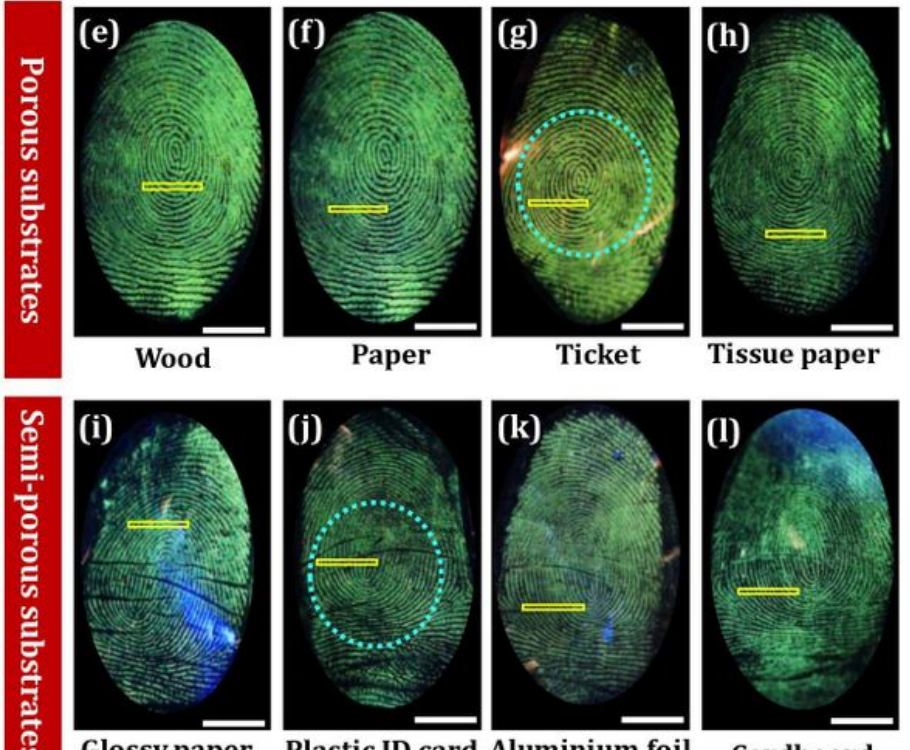

Glossy paper

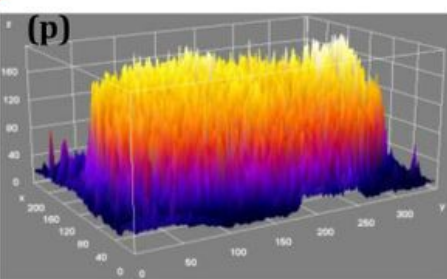

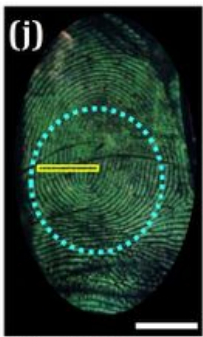
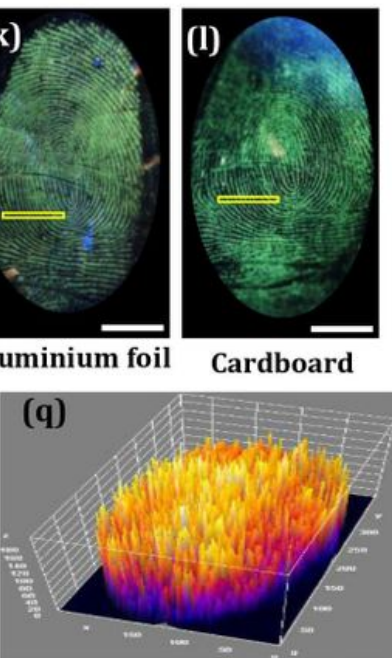

Cardboard

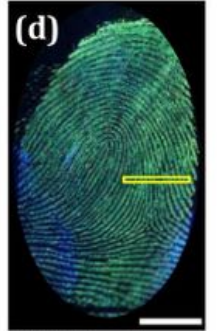

Mobile phone

Tissue paper
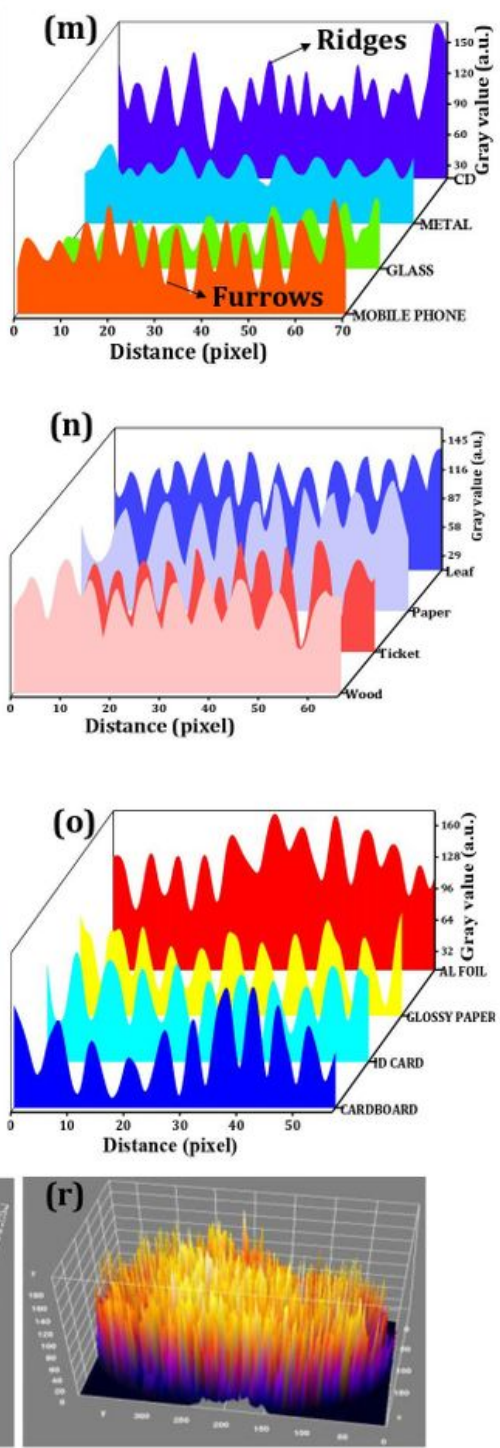

Figure 4 (a-d) LFPs visualized using optimized LZOT: $\mathrm{NH}_{4} \mathrm{Cl}$ (4 wt. \%) NPs on various nonporous surfaces followed by powder dusting technique; (e-h) Developed FPs on various porous surfaces under UV $254 \mathrm{~nm}$ light; (i-1) RGB images of FPs developed using optimized NPs on the semi-porous surfaces; (m-o) Gray scale profiles of marked yellow box on the developed FPs of corresponding row; (p-r) 3D interactive plots of the circled portion of the FPs images (b), (g) and (j), respectively (Scale bar: $5 \mathrm{~mm}$ ).

\section{Figure 4}

Please See image above for figure legend. 

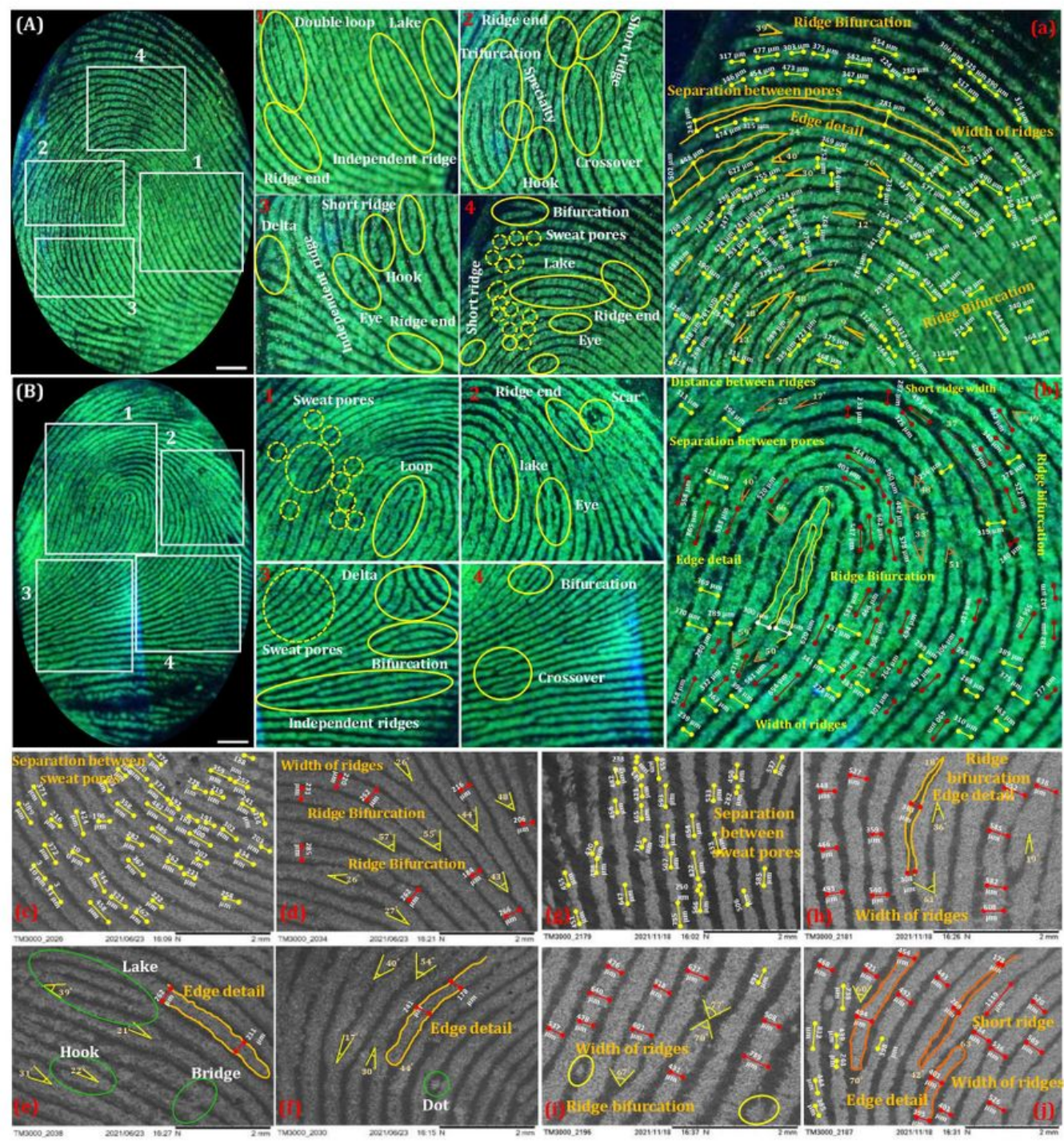

Figure 5 (A \& B) Photographed RGB images of the FPs of two different donors developed using LZOT: $\mathrm{NH}_{4} \mathrm{Cl}$ (4 wt. \%) NPs under UV $254 \mathrm{~nm}$ light; (1-4) Enlarged portions of the FPs of (A) \& (B), revealing detailed ridge details, including level I-III characteristics; (a \& b) Magnified RGB images portion of the FPs, which showing most authenticated level-III ridge features; (c-j) SEM images of the developed FPs, revealing positions of the sweat pores, distance between successive pores, bifurcation and hook angle, shape of the ridge end, width of the ridges, ridge end angle details (Scale bar: $5 \mathrm{~mm}$ ).

\section{Figure 5}

Please See image above for figure legend. 

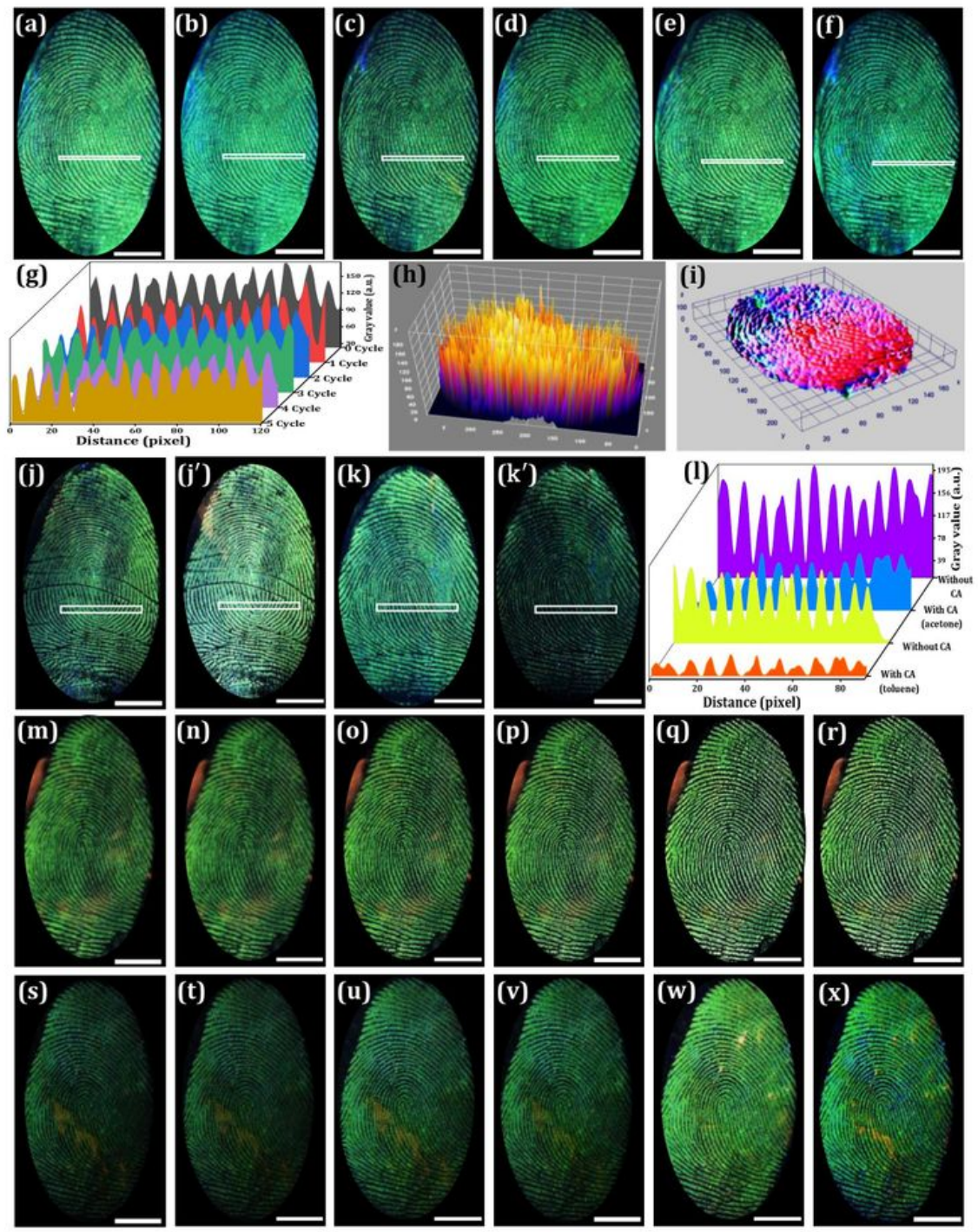

Figure 6 (a-f) Photographed images of the as developed and physically scraped FPs up to 5 cycles, which were visualized using LZOT:NH $\mathrm{NH}_{4} \mathrm{Cl}$ (4 wt. \%) NPs under UV $254 \mathrm{~nm}$ light; (g) Gray scale pixel profiles in the white box region of the (a-f), showing distinct ridges and furrows due to excellence binding of the NPs over LFPs surface; (h \& i) 3D interactive plots of the FPs before and after abrasion; RGB photographs of the visualized FPs under UV 254 $\mathrm{nm}$ light irradiation ( $\mathrm{j} \& \mathrm{k}$ ) before chemical treatment and (j' \& k') after abrasion; (l) Pixel profiles in the white box region of the (j, j', k, k'); Photographed images of the FPs developed using optimized NPs on the glass surface followed by powder dusting technique under (m-r)

\section{Figure 6}

Please See image above for figure legend. 
UV $254 \mathrm{~nm}(\mathrm{~s}-\mathrm{x})$ UV $365 \mathrm{~nm}$ light irradiation with different time periods $(0-5 \mathrm{~h})$ (Scale bar: 5 $\mathrm{mm})$.
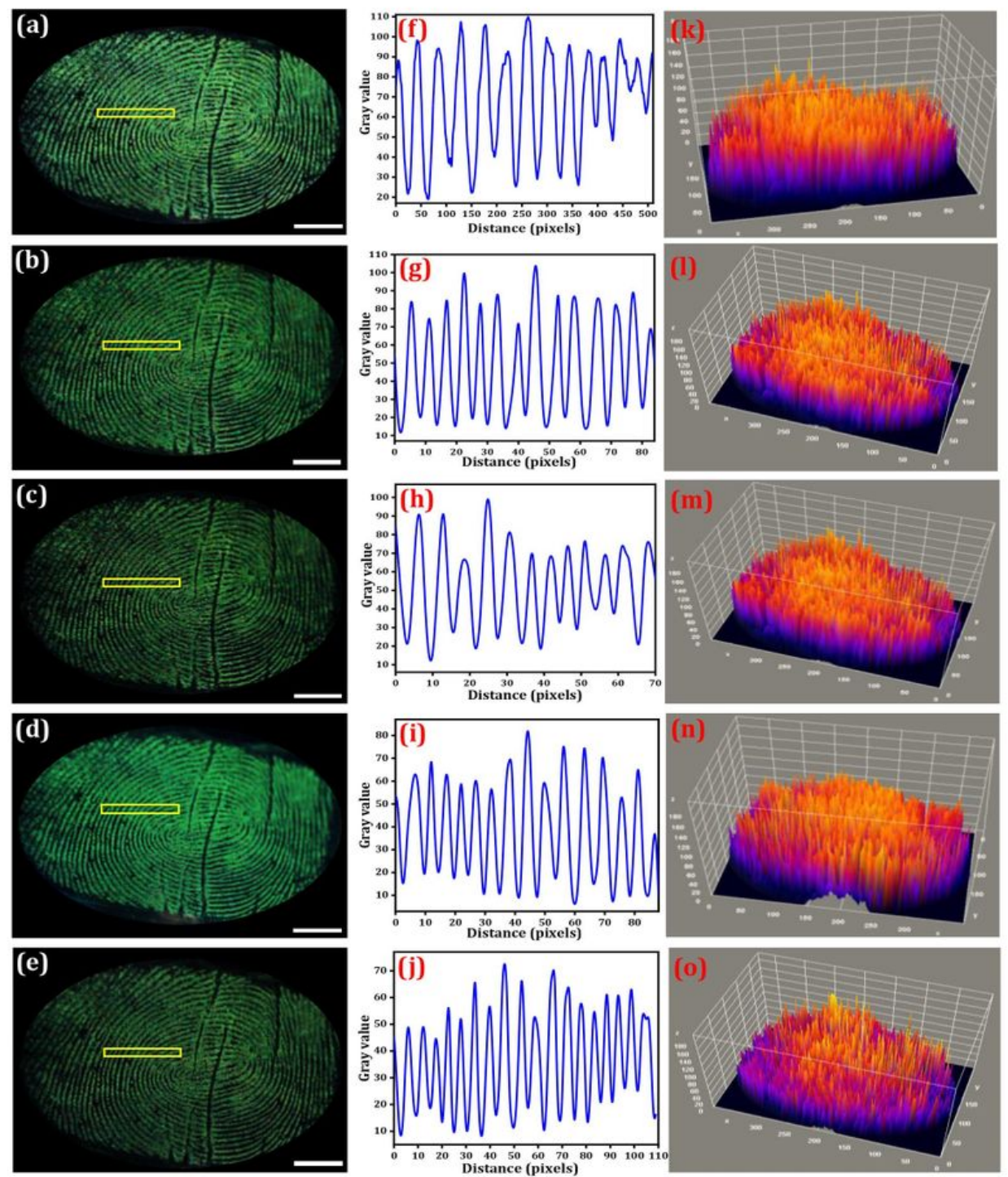

Figure 7. LFPs on the glass surfaces aged for different time periods and visualized using optimized NPs under UV $254 \mathrm{~nm}$ light exposure (a) 0 day, (b) 6 days, (c) 12 days, (d) 18 days, (e) 24 days; (f-j) Pixel plots yellow box region of the corresponding FPs of (a-e); (k-o) 3D interactive plots of the corresponding FPs of the same row (Scale bar: $5 \mathrm{~mm}$ ).

\section{Figure 7}

Please See image above for figure legend.

\section{Figure 8}

Please See image above for figure legend. 


\section{Supplementary Files}

This is a list of supplementary files associated with this preprint. Click to download.

- Supplimentorylnformation.docx 